\title{
Importance of Non-uniform Boundary Migration for Recrystallization Kinetics
}

\author{
Lin, Fengxiang; Zhang, Yubin; Pantleon, Wolfgang; Juul Jensen, Dorte
}

Published in:

Metallurgical and Materials Transactions A: Physical Metallurgy and Materials Science

Link to article, DOI:

10.1007/s11661-018-4846-2

Publication date:

2018

Document Version

Peer reviewed version

Link back to DTU Orbit

Citation (APA):

Lin, F., Zhang, Y., Pantleon, W., \& Juul Jensen, D. (2018). Importance of Non-uniform Boundary Migration for Recrystallization Kinetics. Metallurgical and Materials Transactions A: Physical Metallurgy and Materials Science, 49(11), 5246-5258. https://doi.org/10.1007/s11661-018-4846-2

\section{General rights}

Copyright and moral rights for the publications made accessible in the public portal are retained by the authors and/or other copyright owners and it is a condition of accessing publications that users recognise and abide by the legal requirements associated with these rights.

- Users may download and print one copy of any publication from the public portal for the purpose of private study or research.

- You may not further distribute the material or use it for any profit-making activity or commercial gain

- You may freely distribute the URL identifying the publication in the public portal 


\title{
Importance of non-uniform boundary migration for
} recrystallization kinetics

3

4

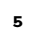

$\cdot{ }^{2}$ Fengxiang Lin*1, Yubin Zhang ${ }^{2}$, Wolfgang Pantleon², and Dorte Juul Jensen²

${ }^{1}$ Université catholique de Louvain, Institute of Mechanics, Materials and Civil Engineering (iMMC), 1348 Louvain la Neuve, Belgium

${ }^{2}$ Department of Mechanical Engineering, Technical University of Denmark, 2800 Kgs. Lyngby, Denmark

\begin{abstract}
Recrystallization kinetics are studied by three characterization methods: post-mortem electron microscopy, in-situ three dimensional X-ray diffraction (3DXRD) and ex-situ electron microscopy. Coldrolled copper is used as a model material. The post-mortem analysis shows that the average migration velocity of unimpinged recrystallizing boundaries decreases strongly with annealing time, leading to a low Avrami exponent. For individual grains, the in-situ 3DXRD measurement reveals that the growth rates decrease significantly shortly after nucleation. This is explained by the ex-situ characterizations, which show that different segments of the recrystallizing boundaries migrate with significantly different velocities, and some boundaries, although unimpinged, remain stationary. This non-uniform migration of recrystallizing boundaries leads to an amoeba-like growth, and is proposed to be responsible for the decrease of the average boundary migration velocity, because the fraction of slowly moving/stationary boundaries increases during the recrystallization. Reasons for stationary boundaries are discussed based on a quantitative analysis of the local deformed microstructure. It is concluded that non-uniform boundary migration has a significant influence on recrystallization kinetics and needs to be included in recrystallization models.
\end{abstract}

Keywords: Recrystallization, EBSD, 3DXRD, heterogeneity, grain boundary migration

\footnotetext{
*fengxiang.lin@uclouvain.be
} 


\section{${ }_{24} 1$ Introduction}

Recrystallization is of key importance for thermomechanical processing of metals and alloys. When a deformed metal is heat-treated, new nearly defect-free grains, here termed recrystallized grains, emerge and grow to replace the deformed matrix. After recrystallization, the density of dislocations introduced during deformation is largely reduced. Recrystallization typically also leads to a significant change in grain size, shape and texture compared to the deformed and the original material. It is thus one of the most effective approaches to alter the mechanical and physical properties of metals and alloys.

To control the recrystallization process, the transformation kinetics during recrystallization needs to be quantified. The classical model describing transformation kinetics was proposed by Johnson and Mehl [1], Avrami [2] and Kolmogorov [3] for phase transformations, but is generally used also for recrystallization. In this so-called JMAK model, the increase of the recrystallized volume fraction $\left(V_{V}\right)$ during isothermal annealing is expressed as:

$$
V_{V}=1-\exp \left(-k t^{n}\right)
$$

where $t$ is the annealing time, and $k$ and $n$ are two parameters. $n$ is often termed the Avrami exponent. The theoretical derivation of the JMAK model assumes that the nucleation sites are randomly distributed in space. When all the recrystallized grains grow in 3D at a constant boundary migration velocity, the Avrami exponent $n$ equals 3 for site saturated nucleation (i.e. all the nuclei appear instantaneously at the beginning of recrystallization), and $n$ equals 4 for the situation of a constant nucleation rate. This is in the following referred to as the idealized JMAK model. Unfortunately, the idealized JMAK model often fails in two aspects: the exponent $n$ has frequently been observed to have values much lower than 3 for 3D growth (e.g. [4]), and is not always constant throughout the recrystallization process, but varies as a function of time (e.g. [5]).

The shortcomings of the idealized JMAK model to describe typical recrystallization kinetics can be attributed to its assumptions. In reality, nucleation sites are often not randomly distributed. Local regions with high stored energy and large misorientations are preferred nucleation sites, e.g. regions near triple junctions [6, 7], transition bands [8], shear bands [9], and large secondary particles [10, 11]. Clustered nucleation, which in turn leads to early impingement of recrystallized grains, on average retards the recrystallization process, as compared to random nucleation. Moreover, migration velocities of the recrystallizing boundaries are often not constant but decrease with annealing time. For example, English and Backofen [12] reported an average boundary migration velocity decreasing as $t^{-1}$ in hotworked silicon iron. Others reported boundary migration velocities decreasing as $t^{-\alpha}$, with an exponent 
${ }_{54} \alpha$ between 0 and 1 (e.g. $\left.[13,14]\right)$.

${ }_{55}$ Statistically, the nucleation and growth conditions during recrystallization can be deduced using 56 the Microstructural Path Method (MPM) suggested by Vandermeer et al. ([15]). This method relies

57 on a number of microstructural parameters determined experimentally for a series of partially recrys58 tallized samples using stereological principles. This type of post-mortem analysis gives an adequate 59 quantification of the average nucleation and growth conditions, but does not provide information on 6o the local physical mechanisms. Recently, in-situ and ex-situ experiments using advanced synchrotron ${ }_{61}$ X-ray methods have been conducted mapping directly the nucleation and growth of individual grains.

${ }_{62}$ For example, using 3D X-ray diffraction (3DXRD) [16-18] the nucleation incubation time and growth ${ }_{63}$ rate of individual nuclei/grains can be determined for bulk samples. With near-field high-energy X${ }_{64}$ ray diffraction microscopy (nf-HEDM)[19] and differential aperture X-ray microscopy (DAXM) [20], the ${ }_{65}$ nucleation sites in the deformed matrix can be pinpointed. However, all these techniques are not suit66 able for characterization of hundreds of grains, which are necessary for a statistically-sound analysis of ${ }_{67}$ recrystallization kinetics. Furthermore, in-situ and ex-situ experiments using electron microscopy ([21${ }_{68}$ 24]) have been performed. However, characterization on a 2D surface may not be representative for 69 bulk behaviour.

In this work, we propose a novel approach by combining three methods, namely post-mortem electron microscopy, in-situ 3DXRD and ex-situ electron microcopy, for a comprehensive analysis of recrystallization kinetics. This combined approach overcomes the major shortcomings of the individual methods, and more importantly covers characterization on three different length scales: i) based on the

\section{s 2 Experimental}

\section{${ }_{81} \quad 2.1 \quad$ Material}

82 Oxygen free high conductivity copper was used in this study. We have chosen this material because it ${ }_{83}$ has been extensively studied in the past but yet its recrystallization kinetics have not been successfully 
84 explained, and it can serve as a model material for many typical metals. The chemical composition was measured using optical emission spectroscopy, and is listed in Table I. The starting material had a grain size of $22 \mu \mathrm{m}$, and a weak initial texture [18]. The sample was cold rolled to $90 \%$ reduction in thickness in several passes using a rolling mill with a roller diameter of $340 \mathrm{~mm}$. The ratio of the contact length over the average thickness $l / h$ was between 0.5 to 5 for each pass to ensure homogeneous rolling [25]. [26].

Table I: Chemical composition (weight percentage) of the material.

\begin{tabular}{cccc}
\hline $\mathrm{Cu}$ & $\mathrm{Ni}(\%)$ & $\mathrm{Mg}(\%)$ & $\mathrm{Al}(\%)$ \\
\hline Balance & 0.002 & 0.002 & 0.002 \\
\hline
\end{tabular}

\subsection{Vickers hardness test}

93 Samples from the $90 \%$ cold-rolled plate were isothermally annealed in an air furnace at $413 \mathrm{~K}, 423 \mathrm{~K}$ and

$94 \quad 433 \mathrm{~K}$ for various time periods (Figure 1a). The microhardness of each annealed sample was examined

95 using a Struers DuraScan fully automatic Vickers hardness tester. A load of $200 \mathrm{~g}$ was applied for $10 \mathrm{~s}$

96 during the tests.

Fig. 1: Sketches showing the thermal treatments on the $90 \%$ cold-rolled plate. (a) Annealing for hardness tests; (b) Annealing for post-mortem EBSD characterizations; (c) Annealing for in-situ 3DXRD measurements; (d) Annealing for ex-situ EBSD characterizations.
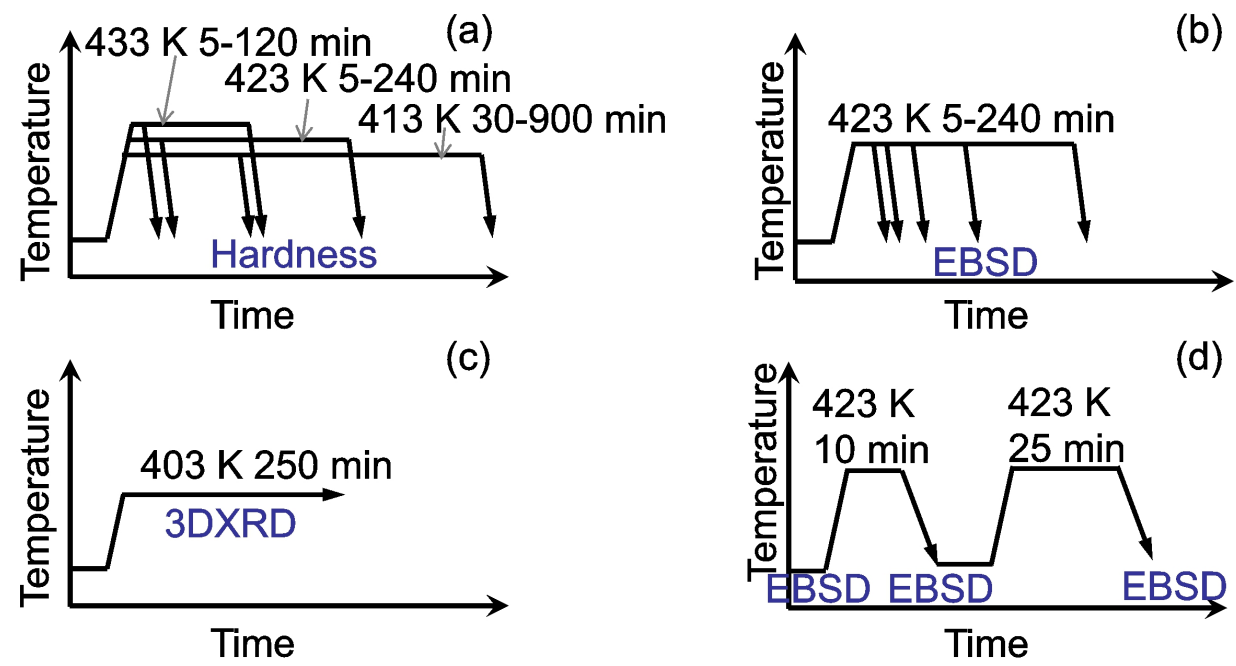


\subsection{Post-mortem EBSD characterization for kinetics analysis}

The 90\% cold-rolled sample was isothermally annealed at $423 \mathrm{~K}$ for time periods from 5 min to $240 \mathrm{~min}$ (see Figure 1b). This heat treatment results in samples with recrystallized volume fractions between $5 \%$ and $95 \%$, which are used for kinetics analysis.

The microstructures of the partially recrystallized samples were characterized using EBSD with a step size of $1 \mu \mathrm{m}$ on the longitudinal sections (defined by the rolling direction (RD) and the normal direction (ND)). For each sample, two EBSD scans from widely separated sample areas were carried out, each covering an area of $300 \mu \mathrm{m}$ by $300 \mu \mathrm{m}$.

The recrystallized grains in the partially recrystallized microstructures were identified automatically from the EBSD data by the method described in [27] using the following three criteria: 1) misorientations inside the recrystallized grains should be less than $1^{\circ} ; 2$ ) the equivalent circular diameter (ECD) of the recrystallized grains should be larger than $3 \mu \mathrm{m} ; 3$ ) each recrystallized grain should be at least partially surrounded (more than 6 pixels along the grain boundary) by high angle boundaries (HABs) to the deformed matrix, where HABs are defined as boundaries with misorientation angles larger than $15^{\circ}$. In copper samples, annealing twins are common. In this work, if not stated otherwise, all twin boundaries (maximum $2^{\circ}$ deviation from the exact $60^{\circ}\langle 111\rangle$ twin relationship) were ignored during reconstruction of the recrystallized grains. In other words, a parent grain and all of its twins were considered as a unity.

We determined the following microstructural parameters for the analysis: the recrystallized volume fraction $\left(V_{V}\right)$, the interfacial area between the recrystallized grains and the deformed matrix per unit volume $\left(S_{V}\right)$, the number of recrystallized grains per unit volume $\left(N_{V}\right)$, the Cahn-Hagel boundary migration velocities $\left(G_{C-H}\right)$, and the contiguity ratio $\left(C_{\operatorname{RexRex}}\right)$. The contiguity ratio is a measure of the fraction of impinged recrystallizing boundaries among all the recrystallizing boundaries. Stereological principles were applied to deduce these volumetric parameters based on parameters determined from 2D characterizations using the following equations [28]:

$$
V_{V}=A_{\text {Rex }} / A_{\text {Total }}
$$

121

$$
S_{V}=4 L_{\text {RexDef }} / \pi A_{\text {Total }}
$$

122

$$
N_{V}=16 V_{V} / 9 \pi D^{3}
$$

$$
G_{C-H}=\left(d V_{V} / d t\right) / S_{V}
$$

$$
\begin{array}{r}
C_{R e x \operatorname{Rex}}=2 S_{V, \operatorname{Rex} \operatorname{Rex}} /\left(2 S_{V, \operatorname{Rex} \operatorname{Rex}}+S_{V}\right) \\
S_{V, \operatorname{RexRex}}=4 L_{\operatorname{Rex} \operatorname{Rex}} / \pi A_{\text {total }}
\end{array}
$$


where $A_{\text {Rex }}$ is the area of all the recrystallized grains, $A_{\text {Total }}$ is the total area of the characterized region, $L_{\text {RexDef }}$ and $L_{\text {RexRex }}$ are the total length of the interface between recrystallized grains and the deformed matrix, and between two recrystallized grains, respectively, $D$ is the average linear intercept length of the recrystallized grains, $d V_{V} / d t$ is the time derivative of the recrystallized volume fraction, and $S_{V, \operatorname{Rex} R e x}$ is the interfacial area per unit volume between two recrystallized grains.

\subsection{DXRD in-situ measurement}

The 3DXRD experiments were conducted at the beamline P07 at PETRAIII, Deutsches ElektronenSynchrotron (DESY) using monochromatic X-rays of $50 \mathrm{keV}$. The sample for the 3DXRD in-situ measurement was cut from the cold-rolled plate and electropolished to avoid nucleation from surface imperfections. The volume illuminated by $\mathrm{X}$-rays was about $500 \times 500 \times 750 \mu \mathrm{m}^{3}$. During the measurements, an X-ray transparent furnace with an inert gas atmosphere was used to anneal the sample at $403 \mathrm{~K}$ (see Figure 1c). During annealing, the sample was rotated around its vertical axis from $\omega=0^{\circ}$ to $\omega=30^{\circ}$ by sweeping intervals of $0.5^{\circ}$, while diffraction images were acquired at the same time. Each $30^{\circ}$ sweep took $5.7 \mathrm{~min}$, which was hence the time resolution of the present experiment. The annealing temperature of $403 \mathrm{~K}$ was chosen to be lower than that used for the post-mortem investigations, so that the time resolution of $5.7 \mathrm{~min}$ was significantly shorter than the time needed for full recrystallization, and thus it became possible to follow the growth of individual grains in-situ with this time resolution. In total 42 sweeps were conducted, and the entire measurement took about $250 \mathrm{~min}$.

Before annealing, the diffraction images were composed of Debye-Scherrer rings from the deformed matrix. During annealing, diffraction spots from recrystallized grains appeared when the Bragg condition was fulfilled. The intensities of the diffraction spots are a linear function of the volume of the recrystallized grains, and the volumes of the recrystallized grains were determined using the method described in the supplementary material of [29]. The diffraction spot of a particular recrystallized grain was first identified from a diffraction image collected during the last $30^{\circ}$ sweep, and then traced back to the diffraction images from earlier sweeps. Diffraction from 8 crystal planes $(\{111\},\{200\},\{220\}$, $\{311\},\{222\},\{400\},\{331\},\{420\})$ was recorded. For a grain with twins the $\{111\},\{220\}$ and $\{222\}$ diffraction spots contain contributions from the grain itself plus some, but not all of the twins. In this work, we therefore only used the $\{200\}$ and $\{400\}$ diffraction spots to avoid partially including twin volumes. Each growth curve thus reflects the growth of one grain without its twins. 


\subsection{Ex-situ EBSD characterization}

Ex-situ EBSD measurements were performed on one sample after different intervals of annealing. First, the deformed microstructure on the longitudinal section was characterized using EBSD with a step size of $0.1 \mu \mathrm{m}$. Two annealing steps were performed: a first step at $423 \mathrm{~K}$ for $10 \mathrm{~min}$, and a second at the same temperature for an extra $25 \mathrm{~min}$ (Figure 1d). For each annealing step, the sample was enclosed in a vacuum glass tube with $50 \mathrm{kPa}$ Ar (purity 99.999\%). After each annealing step, the sample was remapped using EBSD at the same surface location.

A slight misalignment of the EBSD maps before and after annealing was observed. This misalignment was corrected using an affine transformation [30] with reference to the map after the second annealing step.

The stored energy in the deformed microstructure was estimated by summing the energies of all boundaries within the area of interest using the method introduced in [31]. The boundary energy per unit area was calculated using the Read-Shockley equation:

$$
\gamma= \begin{cases}\gamma_{m}\left(\theta / \theta_{m}\right)\left(1-\ln \left(\theta / \theta_{m}\right)\right), & \text { if } \theta \leq \theta_{m} \\ \gamma_{m}, & \text { if } \theta>\theta_{m}\end{cases}
$$

where $\gamma_{m}$ is the energy per unit area of a high angle boundary, $\theta$ is the boundary misorientation, and $\theta_{m}$ is the misorientation angle above which $\gamma$ is independent of the misorientation angle. In this work, we used $\gamma_{m}=0.625 \mathrm{~J} / \mathrm{m}^{2}$, and $\theta_{m}=15^{\circ}$. All boundaries with misorientation angles larger than $2^{\circ}$ were taken into account in the calculation of the stored energy. To visualize the local variation of the stored energy, we calculated for each pixel of an EBSD map the stored energy density in a square region of $0.7 \times 0.7 \mu \mathrm{m}^{2}$ around this pixel. It is noted that the stored energy determined by this method only includes dislocations that contribute to dislocation boundaries with misorientation angles larger than $2^{\circ}$, and the method will thus tend to underestimate the stored energy. 


\section{Results}

\subsection{Recrystallization kinetics}

\subsubsection{Recrystallization kinetics determined by hardness}

The decrease in hardness as a function of annealing time is shown in Figure 2a for temperatures from $413 \mathrm{~K}$ to $433 \mathrm{~K}$. The estimated time corresponding to $50 \%$ hardness reduction (i.e. the hardness value equals to $\left(H V_{D e f}+H V_{\text {Rex }}\right) / 2$, where $H V_{\text {Def }}$ and $H V_{\text {Rex }}$ are the hardness in the deformed and fully recrystallized state, respectively) is used as the characteristic recrystallization time $\left(t_{R}\right)$ at each temperature. Figure $2 b$ shows the dependence of $\ln \left(t_{R}\right)$ on $1 / T$. For the present data, an activation energy $Q$ of $151 \mathrm{~kJ} / \mathrm{mol}$ is found using the Arrhenius equation. In spite of the narrow temperature interval used here, which means that the accuracy in determination of $Q$ is limited, it is satisfying to notice that the observed value of $151 \mathrm{~kJ} / \mathrm{mol}$ is well within the range of $Q$ values from $85 \mathrm{~kJ} / \mathrm{mol}$ to $170 \mathrm{~kJ} / \mathrm{mol}$, reported for $3 \mathrm{~N}$ copper (purity $>99.9 \%$ ) [32].

Fig. 2: (a) Vickers microhardness as a function of time for annealing at three temperatures. The error bars show the standard error of the mean for measurements on the same sample. (b) Temperature dependence of $t_{R}$, where $t_{R}$ is the time for $50 \%$ hardness reduction.
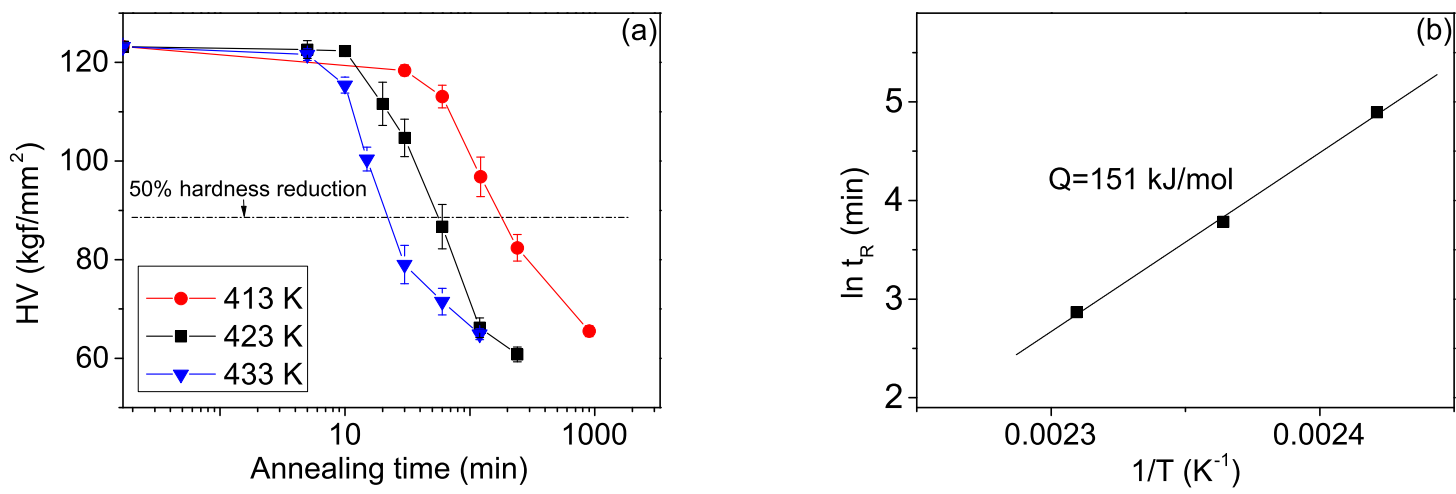

\subsubsection{Evolution of $V_{V}$ and $S_{V}$ during isothermal annealing at $423 \mathrm{~K}$}

The recrystallized volume fraction during isothermal annealing at $423 \mathrm{~K}$ was determined from the EBSD measurements, and is shown as a function of time in an Avrami plot in Figure 3a, i.e. $-\ln \left(1-V_{V}\right)$ vs. $t$ on a $\log _{10}-\log _{10}$ scale. For idealized JMAK kinetics (Eq. 1), all the data points should follow a straight line, with a slope corresponding to the Avrami exponent $n$. For the present data, a straight line can be fitted to the points corresponding to annealing times from $10 \mathrm{~min}$ to $120 \mathrm{~min}$, whereas data points outside this range show obvious deviations. The slope of the fitted line is 1.29 , which is much lower than 
Fig. 3: Evolution of the recrystallized volume fraction $\left(V_{V}\right)$, the interfacial area between recrystallized grains and the deformed matrix per unit volume $\left(S_{V}\right)$, and the contiguity ratio $C_{\operatorname{Rex} \operatorname{Rex}}$. (a) Avrami plot showing $-\ln \left(1-V_{V}\right)$ as a function of annealing time in a double logarithmic plot. (b) $S_{V}$ as a function of $V_{V}$. (c) VMR path plot: $S_{V} /\left(1-V_{V}\right)$ vs. $-\ln \left(1-V_{V}\right)$ in a double logarithmic plot. A solid line is fitted in (c), from which the values of $q$ and $C$ in Eq. 8 are determined. In turn, these $q$ and $C$ values are used to calculate the curve shown in (b). (d) Contiguity ratio $C_{\text {RexRex }}$ vs. $V_{V}$. The solid line in (d) shows the analytical prediction for random nucleation, and the dashed line represents $C_{\operatorname{Rex} \operatorname{Rex}}=V_{V}$.
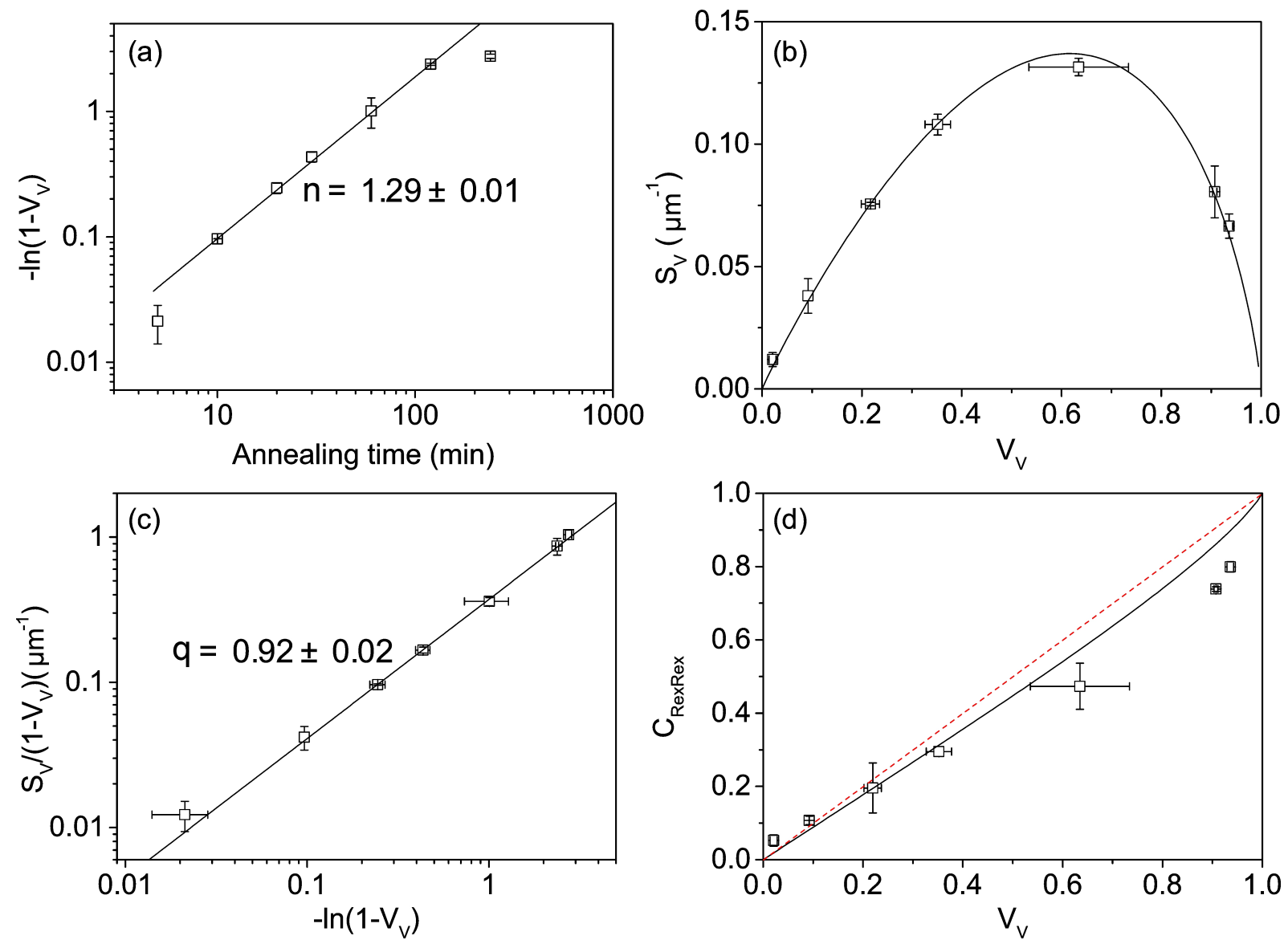

the expected 3 to 4 in the idealized JMAK model. An Avrami exponent around 1 is, however, frequently reported for copper [32], and also for other metals, e.g. steel [33] and Mg [34].

$S_{V}$ represents the area of recrystallizing boundaries per unit volume that have not impinged upon other recrystallized grains, i.e. boundaries free to migrate. Figure $3 \mathrm{~b}$ shows the evolution of $S_{V}$ as a function of $V_{V}$. An interesting feature in Figure $3 \mathrm{~b}$ is that the peak occurs at a $V_{V}$ higher than 0.5 . The peak of $S_{V}$ is expected to appear at $V_{V} \approx 0.5$ for random nucleation [35]. When clustered nucleation occurs, recrystallized grains tend to impinge upon each other earlier, and the peak of $S_{V}$ will shift towards lower values of $V_{V}$, as shown experimentally for aluminium [36] and in analytical and numerical simulations $[37,38]$. A shift of the peak towards higher $V_{V}$ is not so often reported, but Jägle and Mittemeijer [32] reported a very similar shift in a cross-rolled pure copper sample.

For the dependence of $S_{V}$ on $V_{V}$, Vandermeer et al. [15] suggested a path function: 


$$
S_{V}=C\left(1-V_{V}\right)\left(-\ln \left(1-V_{V}\right)\right)^{q}
$$

using two parameters, $C$ and $q$. With Eq. 8 , it is deduced that $q$ larger than 0.69 corresponds to a shift of the peak of the $S_{V}-V_{V}$ curve towards $V_{V}$ larger than 0.5. In Figure 3c, we plot $S_{V} /\left(1-V_{V}\right)$ vs. $-\ln \left(1-V_{V}\right)$ on a $\log _{10}-\log _{10}$ scale in a so-called VMR path plot, and fit the data points to a straight line. With linear regression, we find $q=0.96$ and $C=0.37 \mu \mathrm{m}^{-1}$. These parameters are related to the growth and nucleation conditions, which will be discussed in Section 4.1.

\subsubsection{Spatial distribution of the recrystallized grains}

The contiguity ratio $\left(C_{\text {RexRex }}\right)$ is a parameter relevant to detect microstructural deviations from nucleation at random sites $[39,40]$. When plotting $C_{\text {RexRex }}$ as a function of $V_{V}$, a straight line connecting the points $(0,0)$ and $(1,1)$ is often considered to describe random nucleation (the dashed red line in Figure 3d), but according to [41], the correct theoretical expression for the random nucleation case has a more sophisticated analytical form, which is represented by the solid black curve in Figure $3 \mathrm{~d}$. If nucleation is clustered, points will be above the curve (e.g. [42]). Points below the curve appear when nucleation occurs in an ordered way: for example, if the nuclei are ordered in a simple cubic lattice, $C_{\text {RexRex }}$ will be zero until $V_{V}$ reaches a certain value given by the distance between the nuclei [39].

The contiguity ratio $C_{\text {RexRex }}$ for the present sample follows approximately the curve for random nucleation for $V_{V}<0.5$. Data points for $V_{V}>0.6$ tend to be below the curve (see Figure $3 \mathrm{~d}$ ). This suggests that regions which are hard to recrystallize may be distributed in an ordered manner.

\subsubsection{Nucleation rates and recrystallizing boundary velocities}

The number of recrystallized grains per unit volume $\left(N_{V}\right)$ is plotted as a function of annealing time in Figure 4 a. When a grain and its twins are counted as one grain, $N_{V}$ increases linearly with annealing time until approximately $50 \mathrm{~min}\left(\sim 60 \%\right.$ recrystallized), after which $N_{V}$ saturates. When twins are counted as separated grains, $N_{V}$ increases linearly until approximately $80 \mathrm{~min}(\sim 80 \%$ recrystallized). In both cases, $d N_{V} / d t$ is almost constant before saturation, which means that the nucleation rate $\dot{N}=$ $\left(d N_{V} / d t\right) /\left(1-V_{V}\right)[43]$ is approximately constant before saturation is reached. Extrapolating the data points in Figure $4 \mathrm{a}$ to $t=0$ results in $N_{V}$ close to 0 . Therefore, the nucleation condition for the sample can be described as nucleation with a constant rate until saturation is reached.

To determine the Cahn-Hagel boundary migration velocity $\left(G_{C-H}\right)$ using Eq. $5, d V_{V} / d t$ is derived 
Fig. 4: Nucleation and growth results. (a) Number of recrystallized grains per unit volume $N_{V}$ as a function of annealing time. Annealing twin boundaries (TB) are either ignored or included as normal grain boundaries (GB) when determining the intercept length of the recrystallized grains $D$, which are used in Eq. 4 to determine $N_{V}$. When twin boundaries are ignored, a grain and all of its twins are counted as one grain, otherwise twins are counted as separated grains. (b) Cahn-Hagel boundary migration velocity $\left(G_{C-H}\right)$ as a function of annealing time. The fitted solid line in (b) has a slope of $-0.92 \pm 0.02$
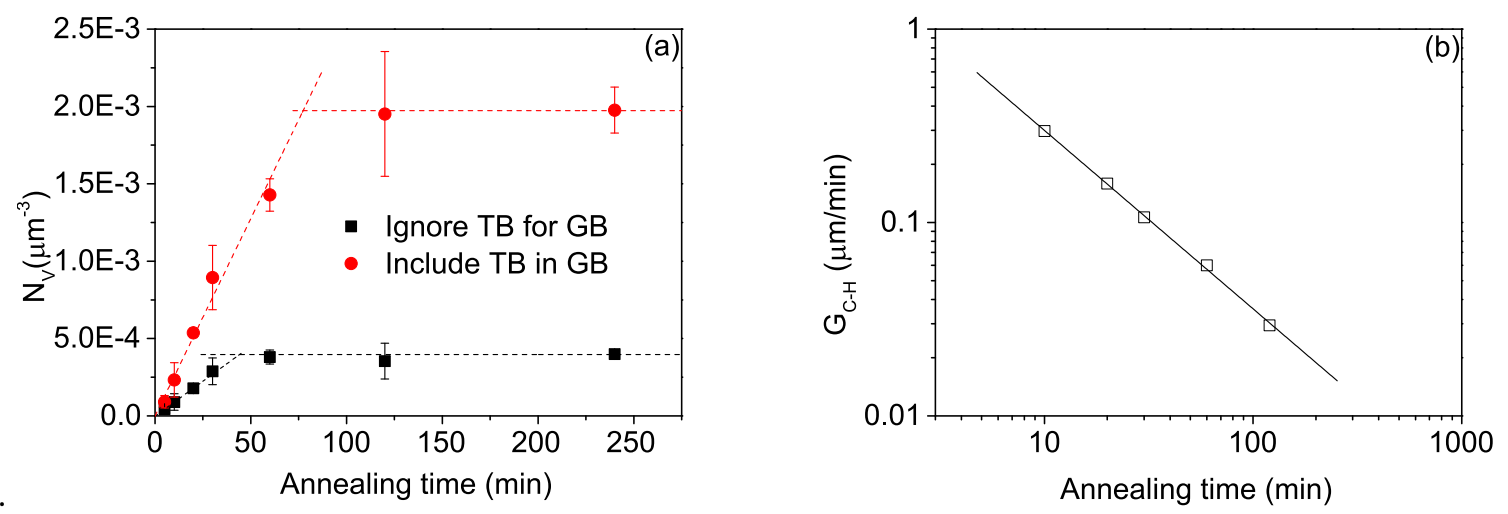

from the JMAK equation (Eq. 1):

$$
d V_{V} / d t=k n \exp \left(-k t^{n}\right) t^{n-1}
$$

where the values of $k=5 \times 10^{-3} \min ^{-1.29}$ and $n=1.29$ are obtained by fitting the data points in Figure 3a. The recrystallized volume fractions for $5 \mathrm{~min}$ and $240 \mathrm{~min}$ annealing time do not follow the straight line in Figure 3a. They are therefore not included in determination of the time derivative $d V_{V} / d t$. Figure $4 \mathrm{~b}$ shows the evolution of $G_{C-H}$ as a function of $t$ on a $\log _{10}-\log _{10}$ scale. The data points can be fitted by a straight line with a slope of -0.92 , which means that $G_{C-H}$ decreases as $t^{-0.92}$ in the selected time interval (10 $\mathrm{min}$ to $120 \mathrm{~min}$ ).

\subsection{Growth of individual grains measured by 3DXRD}

We followed the growth of 835 individual recrystallized grains in-situ. The growth curves of eight individual grains are shown in Figure 5 representing the equivalent sphere diameter (ESD) as a function of time. The growth curves vary from grain to grain, which is similar to measurements for aluminium $[16,17]$. For 3DXRD results, the growth rate is defined as the increase of ESD per unit time. We do not observe a linear increase in ESD for any of the growth curves, i.e. no grain follows the idealized JMAK assumption of growth at a constant rate. Instead, most of the grains show a fast growth stage for a limited time period after nucleation, after which the growth rate decreases quickly, reaching a stagnation period. Only very few grains, like the one with the growth curve marked by an arrow, continue to grow again after a stagnation period. The other grains just stop growing or grow only very slowly after reaching the stagnation period. If we use the ESD of each grain at the end of the in-situ measurement as the stagnation size, the recrystallized grains reaches $80 \%$ of their stagnation size on average after 
Fig. 5: Increase of the equivalent sphere diameter (ESD) of individual grains as a function of annealing time, measured by 3DXRD during in-situ annealing at $403 \mathrm{~K}$. The arrow marks the growth curve of a grain that continues to grow again after a stagnation period.

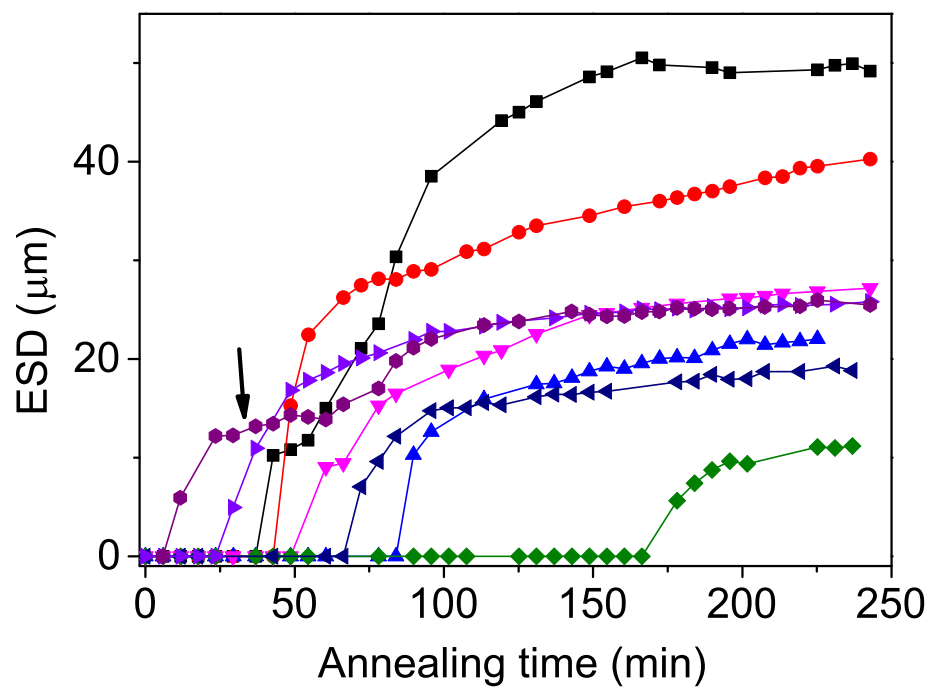

\subsection{Ex-situ measurement of migration of recrystallizing boundaries}

$61 \mathrm{~min}$. One may speculate whether impingement between the recrystallized grains may explain this stagnation. Using the calculated activation energy $Q=151 \mathrm{~kJ} / \mathrm{mol}$ (Figure $2 \mathrm{~b}$ ), it is found that the time to reach $50 \%$ recrystallization at $403 \mathrm{~K}$ is expected to be $370 \mathrm{~min}$. This means that stagnation time in the order of $61 \mathrm{~min}$ is significantly shorter than $t_{R}$. Thus the influence of impingement between different recrystallized grains during the monitored $250 \mathrm{~min}$ is not significant, and the observed stagnation can therefore not be explained by impingement for the present sample. This is further documented by the ex-situ electron microscopy characterization (see Section 3.3). or

To further investigate why most grains only have a short period of fast growth followed by stagnation or very slow growth, an ex-situ EBSD experiment was conducted. Figure 6a-c shows EBSD maps of the same area in the deformed state and after $10 \mathrm{~min}$ and $35 \mathrm{~min}$ annealing at $423 \mathrm{~K}$. It is noted that the area fraction of recrystallized grains on the observed surface is only around 0.1 after 35 min annealing, less than that in a bulk sample as reported in Section 3.1.2. This is not surprising, as the sample is semibulk. This means that only nuclei underneath the surface can grow into the characterized surface and contribute to the recrystallized area, whereas in real bulk samples, as those used for the post-mortem analysis, nuclei from both sides will grow into the characterized surfaces.

Before annealing, the deformed microstructure is composed of bands with different crystallographic orientations (Figure 6a). Most of the bands are approximately parallel to RD. Localized shear bands, 
Fig. 6: Growth of individual grains during ex-situ annealing at $423 \mathrm{~K}$. (a)-(c) Orientation maps in the deformed state (a) and after $10 \mathrm{~min}(\mathrm{~b})$ and $35 \mathrm{~min}$ (c) annealing. Boundaries with misorientations larger than $5^{\circ}$ are shown in black. Twin boundaries are shown in white. (d) Boundaries with misorientation larger than $5^{\circ}$ within the deformed microstructure before annealing. Localized shear bands are marked by arrows. (e) Contours of two recrystallized grains (A1 and A4) after $10 \mathrm{~min}$ and $35 \mathrm{~min}$ are shown on top of the boundary map of the deformed microstructure.
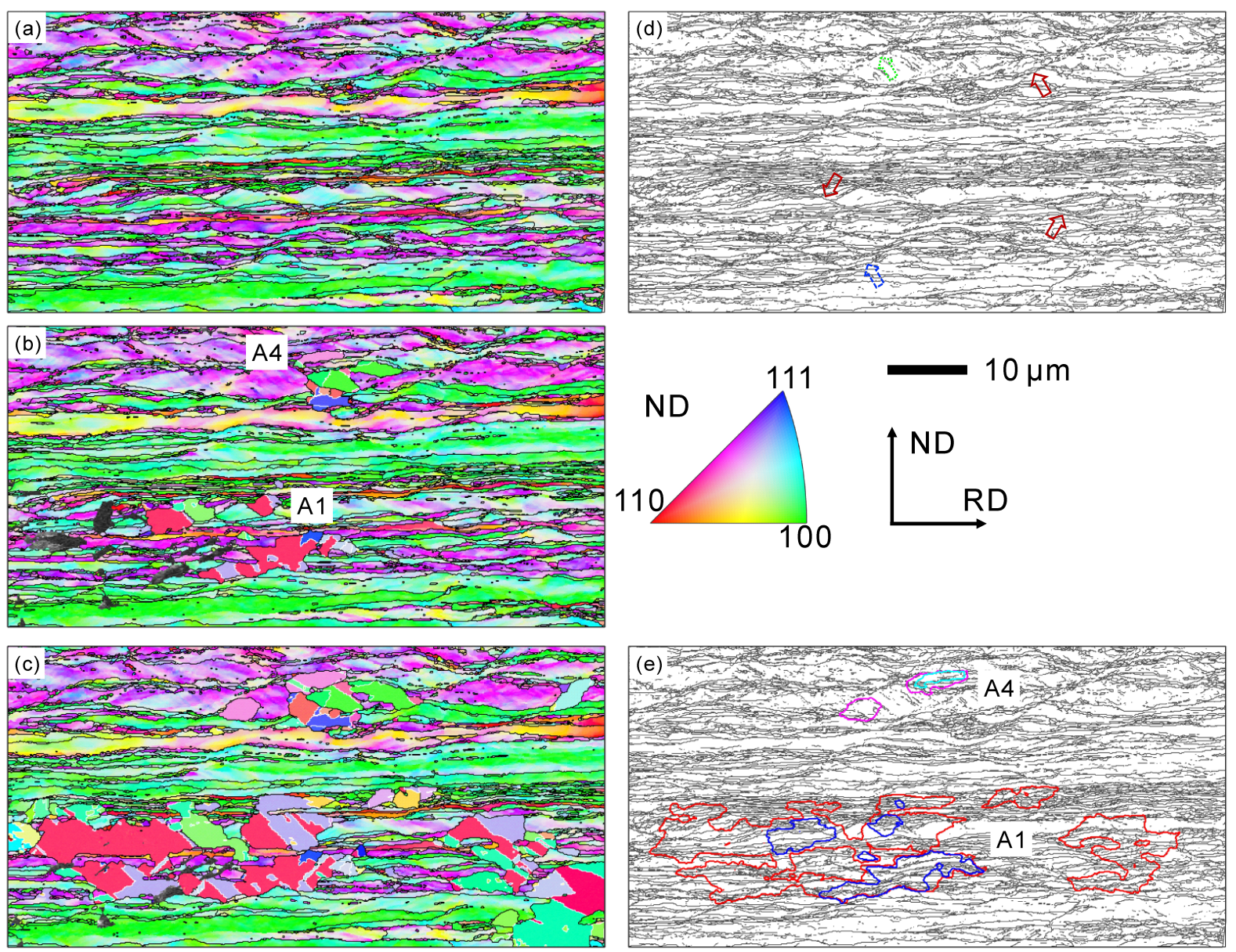

inclined approximately $\pm 35^{\circ}$ to $\mathrm{RD}$, are also observed (marked by arrows in Figure $6 \mathrm{~d}$ ). The deformed sample has a typical rolling texture, consisting of $16 \%$ copper $(\{112\}\langle 111\rangle), 19 \%$ brass $(\{110\}\langle 112\rangle)$ and $42 \% \mathrm{~S}(\{123\}\langle 634\rangle)$ orientations, within a maximum $15^{\circ}$ deviation from the ideal texture components.

Four grains were observed after 10 min annealing. In this work, we focus on the two grains termed A1 and A4 (see Figure 6b), because these two grains are entirely unimpinged after the first annealing step. Due to twinning, each grain contains several parts with different orientations. Moreover, both grains contain parts that are not connected in 2D: the unconnected parts are composed of regions with identical orientations (misorientation $<1^{\circ}$ ). For illustration, the recrystallizing boundaries of the two grains are superimposed on top of the deformed structure in Figure 6e. The overall shape of grain A1 is elongated along RD, whereas near the shear band marked by the dashed (blue) arrow in Figure 6d, a part of the grain appears to be elongated along the shear band direction. The two parts of grain A4 
appear to align along the direction of the shear band marked by the dotted (green) arrow in Figure $6 \mathrm{~d}$.

From Figure 6e, it is seen that different segments of the recrystallizing boundaries move with different velocities, i.e. exhibit non-uniform growth, and some unimpinged segments are almost stationary. Considering the accuracy of alignment between different EBSD maps, a boundary segment is considered stationary, if it shows a displacement less than 2 pixels $(0.02 \mu \mathrm{m})$ during the second annealing step. This is more clearly shown in Figure 7, where the stationary boundary segments are highlighted in green. For grain $\mathrm{A} 1,33 \%$ of the unimpinged boundary segments are stationary during the second annealing step. This fraction is $32 \%$ for grain A4. These stationary boundaries and those moving very slowly contribute to a decrease in the average boundary migration velocity.

Fig. 7: Sketch showing the recrystallizing boundary positions for grains A1 and A4.

$10 \mu \mathrm{m}$
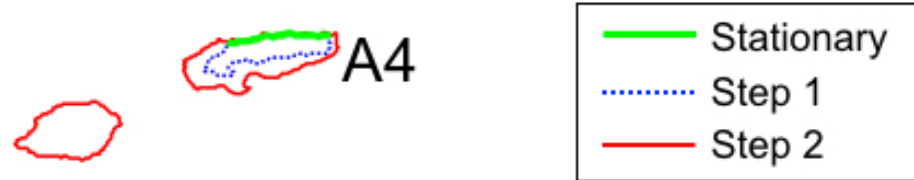
Step 2
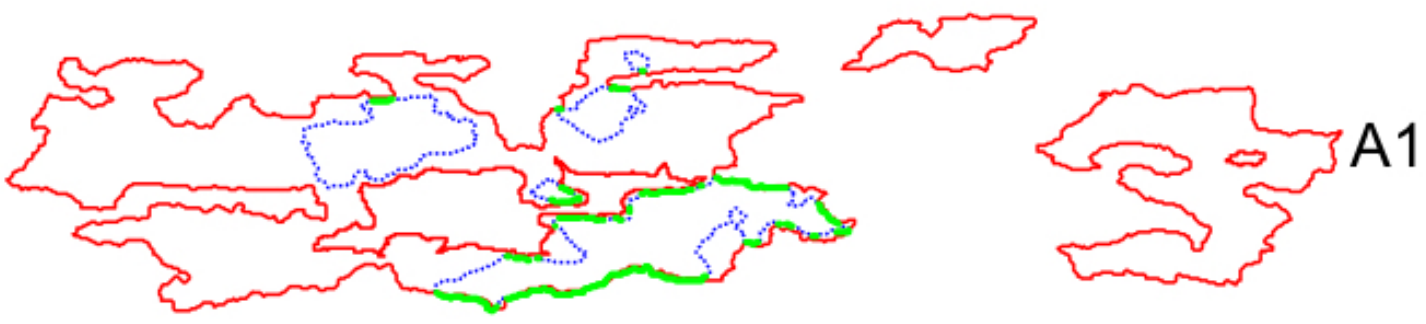

Table II: Grain areas and average stored energy density. $E_{s, m i g}$ is the average stored energy density within the area that the migrating boundaries sweep during each annealing step. $E_{s, s t a}$ is the average stored energy density in the area ahead of the stationary boundaries.

\begin{tabular}{ccccccc}
\hline & $\begin{array}{c}\text { Area } \\
\left(\mu \mathrm{m}^{2}\right)\end{array}$ & $\begin{array}{c}\text { Grain A1 } \\
E_{s, \text { mig }} \\
\left(\mathrm{MJ} / \mathrm{m}^{3}\right)\end{array}$ & $\begin{array}{c}E_{s, \text { sta }} \\
\left(\mathrm{MJ} / \mathrm{m}^{3}\right)\end{array}$ & $\begin{array}{c}\text { Area } \\
\left(\mu \mathrm{m}^{2}\right)\end{array}$ & $\begin{array}{c}\text { Grain A4 } \\
\left(\mathrm{MJ} / \mathrm{m}^{3}\right)\end{array}$ & $\begin{array}{c}E_{s, \text { sta }} \\
\left(\mathrm{MJ} / \mathrm{m}^{3}\right)\end{array}$ \\
\hline Step 1 (0-10 $\mathrm{min})$ & 81.5 & 3.3 & & 7.0 & 2.7 & \\
Step 2 (10-35 $\mathrm{min})$ & 392.2 & 3.1 & 2.7 & 25.3 & 2.9 & 3.1 \\
\hline
\end{tabular}

With the present ex-situ data, it is possible to analyze the deformed microstructure invaded by the recrystallized grains. Similar analysis was performed in [44]. We can thus test, if the stored energy and/or misorientation across the boundaries may explain why some boundaries are stationary while others migrate. Figure 8 shows the local variations of the stored energy density $\left(E_{s}\right)$ determined from the EBSD map before annealing. The local $E_{s}$ varies from 0.5 to $6.2 \mathrm{MJ} / \mathrm{m}^{3}$, and the average $E_{s}$ of this map is $2.8 \mathrm{MJ} / \mathrm{m}^{3}$. For both grains $\mathrm{A} 1$ and $\mathrm{A} 4$, the invaded regions include regions of high and low $E_{s}$. Similarly both high and low $E_{s}$ regions are observed next to the stationary boundaries (see Figure 8 ). 
For a quantitative analysis, we determined an average $E_{S}$ ahead of the stationary boundaries considering regions within $2 \mu \mathrm{m}$ to the stationary boundaries, noted as $E_{s, s t a}$. The average stored energy density within the invaded region, i.e. the area that the migrating boundaries sweep during the annealing step, is noted as $E_{s, m i g}$. As listed in Table II, the average $E_{s}$ ahead of the stationary boundaries is similar to those invaded by the migrating boundaries, and the average $E_{s, m i g}$ for the migrating boundaries are similar during the first and the second annealing steps. For the deformed matrix remaining unrecrystallized after the second annealing step, the stored energy density can be calculated not only from EBSD maps before annealing, but also from maps after each of the first and the second annealing steps, which are $2.9 \mathrm{MJ} / \mathrm{m}^{3}, 2.9 \mathrm{MJ} / \mathrm{m}^{3}$ and $2.7 \mathrm{MJ} / \mathrm{m}^{3}$, respectively. This shows that recovery of the deformed matrix is very limited during the present annealing, which is consistent with other observations reported in literature for copper [45].

Fig. 8: Stored energy density map. The local store energy density is represented in gray scale. The recrystallizing boundaries of grains A1 and A4 after the first and the second annealing steps, and the stationary boundaries are also shown. Two low $E_{s}$ regions ahead of the stationary boundaries or invaded by the recrystallized grains are indicated by arrows.

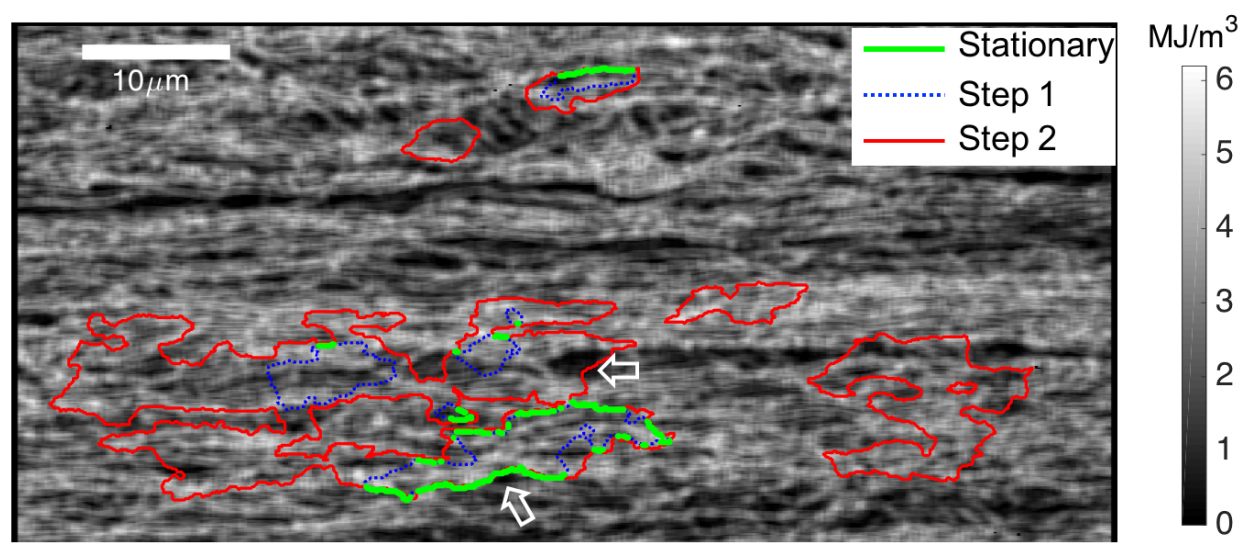

For each pixel in the recrystallized grains, we calculate the misorientation between this pixel and the orientation at the same location in the EBSD map before annealing. With this method, we determined the distribution of misorientations to the invaded deformed microstructure during each of the first and second annealing steps (Figure 9a and b). For both grains, the distributions of the misorientation angles peak at $50^{\circ}-55^{\circ}$ with a misorientation axis close to $\{111\}$. The distributions of misorientations are not significantly different between the first and the second annealing steps. The misorientations across the stationary boundaries are plotted in Figure $9 \mathrm{c}$ and $\mathrm{d}$. The peak of the misorientation angles is shifted to $55^{\circ}-60^{\circ}$ for grain $\mathrm{A} 1$, whereas for grain $\mathrm{A} 4$, more than half of the misorientation angles are less than $15^{\circ}$. 
Fig. 9: Distributions of misorientations between the recrystallized grains A1 (a) and A4 (b) and the invaded deformed regions during the two annealing steps, and distributions of misorientations across stationary recrystallizing boundaries for grains A1 (c) and A4 (d).
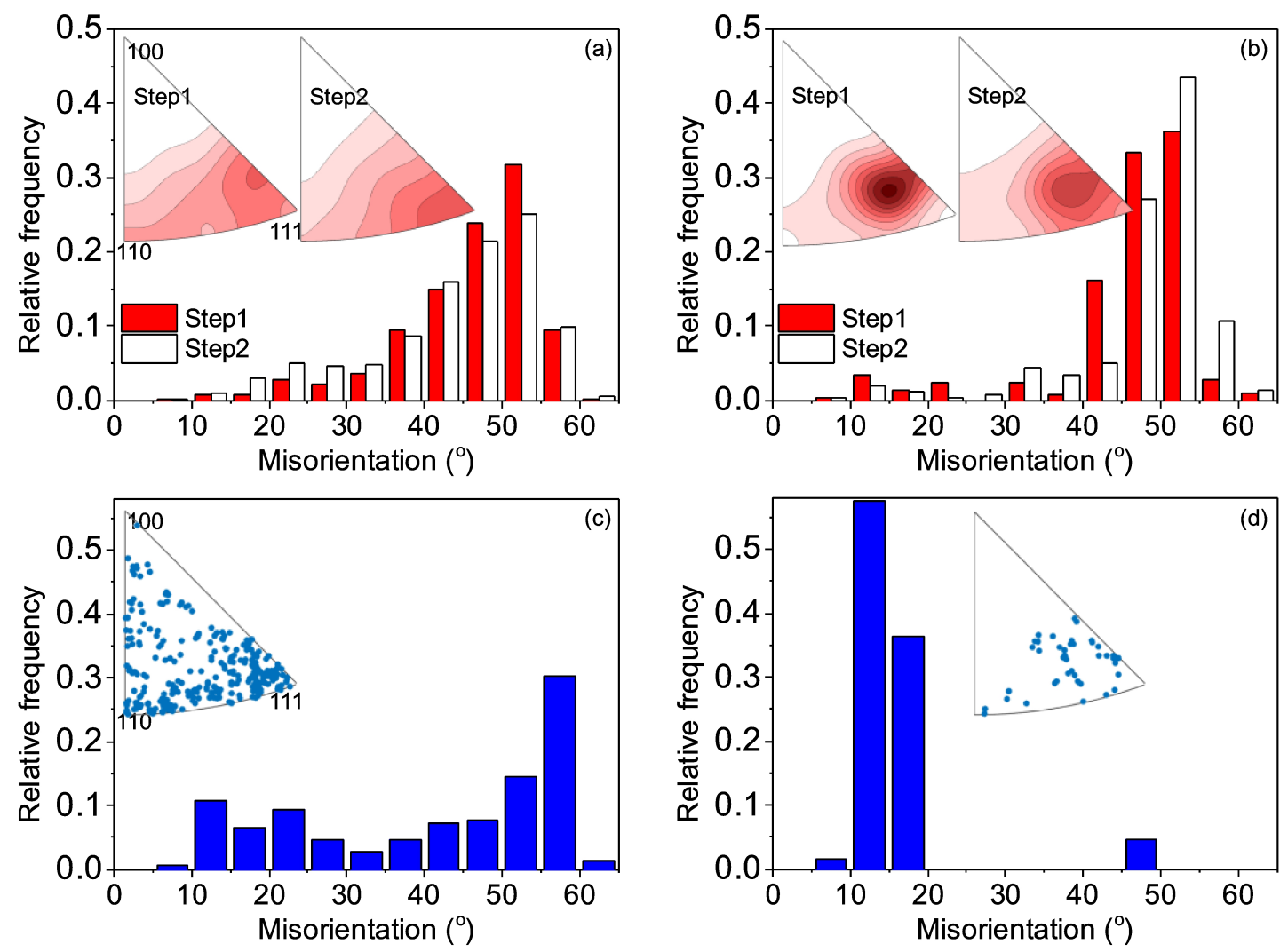

\section{Discussion}

\subsection{Avrami exponent and shift of the peak of the $S_{V}-V_{V}$ curve}

The Avrami exponent $n$ depends on both the nucleation and growth conditions. Vandermeer et al [15] proposed a model for transformation using the assumptions of random nucleation and shape preserved growth. In their model, the nucleation rate $\dot{N}$ and the average boundary migration velocity $G$ of the recrystallized grains are expressed as:

$$
\dot{N}=N_{1} t^{\delta-1}
$$

$$
G=r P t^{r-1}
$$

where $t$ is the annealing time, and $N_{1}, \delta, r$ and $P$ are parameters describing the nucleation and growth conditions. The Avrami exponent $n$ is then equal to $\delta+3 r$. The post-mortem kinetics analysis of this 
sample shows that the average boundary migration velocity $G_{C-H}$ has a time dependence of $t^{-0.92}$ (see Figure $4 \mathrm{~b}$ ), which according to Eq. 11 gives a very small $r$ of 0.08 . Considering that the constant nucleation rate observed experimentally leads to a $\delta$ of 1 according to Eq. 10, the model would predict an Avrami exponent close to the experimentally observed value of 1.29 (Figure 3a).

In the model of Vandermeer, the fitting parameter $q$ of the VMR path function Eq. 8 can also be related to the nucleation and growth conditions using the following equation [15]:

$$
q=\frac{2 r+\delta}{3 r+\delta}
$$

For our sample we find from Figure $3 \mathrm{c}$ a $q$ of 0.96 . According to Eq. 12, the upper limit of $q$ is 1 , which occurs when $\delta \gg r$. For the present sample, the decreasing average growth rate of the recrystallized grains with $r=0.08$ in combination with a constant nucleation rate can rationalize $q$ being approximately 1 . An understanding why the average growth rate of the recrystallized grains/average migration velocity of the recrystallizing boundaries decreases so strongly is therefore essential for the present recrystallization kinetics.

\subsection{Decreasing boundary migration velocities}

As revealed by the in-situ 3DXRD measurement, most grains approach stagnation after a short period of fast growth. The occurrence of such behavior was proposed in [46]. This particular growth behavior can be used to explain the decrease of $G_{C-H}$ with increasing time. Considering the extreme case that each recrystallized grain will reach its stagnation size immediately after nucleation, $G_{C-H}$ will decrease as a function of $t^{-1}$ (see Appendix). In other words, the measured average boundary velocities will show a time dependence close to $t^{-1}$, if the growth period for individual grains is very short. For many other materials, measured average boundary velocities are reported to have a time dependence of $t^{-\alpha}$ with $\alpha$ close to 1 (e.g. $[12,13,35]$ ), which may thus be due to fast growth to a stagnation size, as in the present sample.

This fast growth to a stagnation size can be attributed to non-uniform boundary migration velocities, as revealed by the ex-situ EBSD measurements. Among the unimpinged recrystallizing boundaries, some boundary segments migrate fast, whereas others have low migration velocities or even become stationary. However, fast moving boundaries will not migrate forever with high velocities, they will either impinge upon other recrystallized grains, or slow down when entering a deformed region unfavorable for grain boundary migration. As slowly moving boundaries will not migrate much further, they will be preserved for an extended time period, and the fraction of slowly moving boundaries will 
thus increase with increasing annealing time. Due to this accumulation of stationary boundaries, recrystallized grains will reach a stagnation size without full impingement upon other recrystallized grains. $G_{C-H}$ is the average migration velocity of all the unimpinged boundaries, and as the fraction of slowly moving boundaries increase with annealing time, $G_{C-H}$ will decrease correspondingly even though fast migrating boundaries appear when new nuclei form.

The classic equation for boundary migration velocity is expressed as [47]:

$$
G=M F
$$

where $M$ and $F$ are the boundary mobility and driving force, respectively. The stored energy within the deformed matrix provids driving force for recrystallization. Decrease of the stored energy with increasing annealing time due to recovery of the deformed matrix (e.g. [5]) or variations of local stored energy (e.g. [4, 48-51]) has been frequently used to explain the decrease of the average boundary migration velocity during annealing. Our quantitative analysis based on the ex-situ characterization shows that after two steps of annealing, the recovery of the deformed matrix is very minor, which excludes the possibility of concurrent recovery for slowing down boundary migration. Variations of local stored energy are present in this sample. Conventionally, it is argued that the high $E_{S}$ regions will be invaded first, leaving lower $E_{S}$ regions to be invaded in the following steps. Our results, however, do not agree with this stipulation. Although a few stationary boundary segments seem to stop at a local region with low stored energy (see Figure 8), the average value of $E_{S}$ ahead of the stationary boundaries is not significantly different from that of the invaded regions (Table II). Therefore, neither the reduction in stored energy due to recovery nor variations of local stored energy are the main reasons leading to stationary boundaries for the present sample.

The boundary mobility is the other factor determining the boundary migration velocities. The analysis of the ex-situ results shows that misorientations of stationary boundaries are quite different from those of migrating boundaries (Figure 9). The majority of stationary boundaries of grain A4 has misorientations less than $20^{\circ}$. It is well recognized that low angle boundaries (LABs) have low mobility, which will lead to the so-called "orientation pinning" effect $[13,52]$. The stationary boundary segments observed for grain A4 can be explained by orientation pinning. For grain A1, the stationary boundaries tend to have a large fraction of misorientations larger than $55^{\circ}$, but only approximately $6 \%$ of these misorientations are within $15^{\circ} / \sqrt{3}$ to the ideal twin relationship, and thus an explanation based solely on twins is not appropriate. The dependences of the boundary mobility on the misorientation are very complex [53], and also depend on the boundary plane [54]. With the present 2D ex-situ data, crystallographic planes of the boundaries are unknown, and thus no further analysis of the boundary plane 
effects is possible with the present data.

Another reason for why some boundaries become stationary or migrate only very slowly may be related to the morphology of the deformed microstructure. Recent 3D studies have shown that the local geometrical arrangement of the dislocation boundaries has a strong influence on the local boundary migration $[55,56]$. Migration of recrystallizing boundaries which are perpendicular to the dislocation boundaries are favored. A similar trend is seen in the present sample. In this cold-rolled sample, most of the high angle boundaries are lamellar boundaries parallel to RD. The ex-situ annealing EBSD results show that boundary segments parallel to ND have a tendency to move faster than those parallel to RD. For recrystallizing grains near shear bands, the recrystallizing boundaries appear to migrate following the shear band direction. It is thus suggested that the morphology of the deformed microstructure is also important, and has to be considered when analyzing migration of the recrystallizing boundaries.

\subsection{Growth dimensionality}

In literature, a decrease in $G_{C-H}$ as a function of annealing time has been suggested to be related to non3D/low-dimensional growth [57]. If recrystallized grains grow radially to form plates (2D growth) or lengthen to form rods (1D growth), the $G_{C-H}$ method will still average over the entire unimpinged grain boundaries, and thus not describe the radial/lengthening migration rate well. In both the 1D and 2D growth situations, $G_{C-H}$ will show a decrease as $t^{-1}$ at long annealing time even for a constant velocity [57]. In other words, a low-dimensional growth will result in a similar decrease of the average boundary migration velocity as observed here for non-uniform 3D growth. The concept of low-dimensional growth has also been used to explain a low Avrami exponent. For example, for site saturated nucleation, $n=2$ for 2D growth with a constant radial growth rate, and $n=1$ for $1 \mathrm{D}$ growth with a constant lengthening rate [58]. For low-dimensional growth, the grain shape will change significantly during growth: rods will become longer (1D growth) and plates will enlarge (2D growth) without changing their thickness. For the present sample, this is not the case (see Figure 6).

The present non-uniform growth however has some similarities with non-3D growth, and may thus be falsely interpreted as non-3D growth. Considering 1D growth, a grain will change from a sphere to a rod, as shown in Figure 10a. If the growth occurs in 3D but highly non-uniform with stationary boundary segments, the initial sphere will turn into a sea urchin shape (Figure 10b). This extreme case of nonuniform growth is indeed another type of $1 \mathrm{D}$ growth, but with more than one lengthening direction. In reality, depending on the difference in migration velocities of the fast and slowly migrating boundaries, the growth is more or less like the case shown in Figure 10c, leading to grains with an amoeba shape. As a consequence of the similarities between non-uniform 3D growth and low-dimensional growth, the 
Fig. 10: Sketch showing (a) low-dimensional, non-3D growth, (b) 3D growth with many stationary boundary segments, and (c) 3D growth with boundary segments migrating at different velocities.

(a)

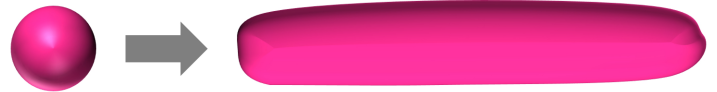

(b)

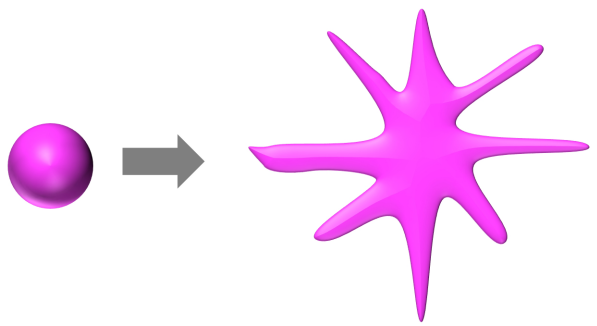

(c)

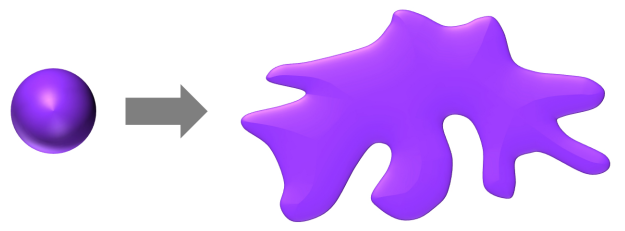

\section{Conclusions}

We have investigated recrystallization kinetics of a polycrystalline copper sample cold-rolled to $90 \%$ reduction in thickness, aiming at understanding why the sample has a low Avrami exponent and strongly decreasing boundary migration velocities, which are observations frequently reported in literature for many materials. The following conclusions are obtained:

1. The strongly decreasing average migration velocity of recrystallizing boundaries is the major reason for the low Avrami exponent.

2. Migration velocities of the recrystallizing boundaries are non-uniform: different segments of the boundaries have significantly different velocities; some continue to move while some become station436 ary. As the fraction of boundaries with low migration velocities accumulates during recrystallization, 7 this non-uniform boundary migration behavior leads to a decrease in the average velocity of the recrys8 tallizing boundaries as a function of annealing time.

3. The non-uniform boundary migration behavior is related to the misorientations with the deformed 
matrix, whereas effects of stored energy are less significant. It is further suggested that the local geometrical arrangement of the dislocation boundaries may affect boundary migration.

4. Non-uniform 3D growth may lead to recrystallization kinetics appearing similar to that for lowdimensional growth. Shapes of the recrystallized grains in a partially recrystallized state can be used to evaluate whether recrystallized grains exhibit low-dimensional or non-uniform growth.

\section{Acknowledgements}

FXL is mandated by the Belgian National Fund for Scientific Research (FSR-FNRS). The authors warmly thank Dr. R.A. Vandermeer for fruitful discussions on MPM. The authors also acknowledge beamtime by DESY under proposal number I-20110560 EC and Dr. N. Schell for assistance in using beamline P07. Dr. Hong Liu is thanked for help in preparation of the manuscript.

\section{Appendix: Cahn-Hagel average boundary migration velocity for in-} stantaneously stagnated growth

Considering the extreme case that the growth rates of the individual grains can be described by a Dirac delta function at $t=t_{\text {nucleation }}$, each recrystallized grain will reach its stagnation size immediately after nucleation. The increase of $V_{V}$ and $S_{V}$ will thus be controlled by nucleation only. This can be analyzed further by using the idea of the extended interfacial area per unit volume $S_{V e x t}$ and the extended recrystallized volume fraction $V_{V e x t}$, which are the fictive density of interfacial area and the fictive recrystallized volume fraction under the theoretical situation that grains are allowed to overlap. If the nuclei are randomly distributed in space, and their shapes are preserved, $V_{\text {Vext }}=-\ln \left(1-V_{V}\right)$, and $S_{\text {Vext }}=$ $S_{V} /\left(1-V_{V}\right)$. The Cahn-Hagel boundary velocity can then be written as $G_{C-H}=\left(d V_{V e x t} / d t\right) / S_{V e x t}$. By expressing the nucleation rate $\dot{N}$ using Eq. 10 , the average $G_{C-H}$ will be:

$$
G_{C-H}=\frac{d V_{V}}{d t} \frac{1}{S_{V}}=\frac{d V_{\text {Vext }}}{d t} \frac{1}{S_{\text {Vext }}}=\frac{v_{\text {Rex }} \dot{N}}{s_{\text {Rex }} \int_{0}^{t} \dot{N} d \tau}=\frac{v_{\text {Rex }}}{s_{\text {Rex }}} \delta t^{-1}
$$

where $v_{\operatorname{Rex}}$ and $s_{\operatorname{Rex}}$ are the average extended volume and average extended surface area of stagnated recrystallized grains, and both can be assumed to be independent of the annealing time. It is seen that in this extreme case, $G_{C-H}$ will decrease as a function of $t^{-1}$. 


\section{${ }_{464}$ References}

${ }_{465}$ [1] W. A. Johnson, R. F. Mehl: Trans. Aime 1939, vol. 135 (8), pp. 396-415.

466 [2] M. Avrami: The Journal of Chemical Physics 1939, vol. 7 (12), pp. 1103-1112.

[3] A. N. Kolmogorov: Bull. Acad. Sci. USSR, Math. Ser 1937, vol. 1, pp. 355-359.

468

[4] H. Luo, J. Sietsma, S. Van Der Zwaag: Metallurgical and Materials Transactions A 2004, vol. 35 (6), pp. 1889-1898.

[5] R. A. Vandermeer, B. Rath: Metallurgical Transactions A 1989, vol. 20 (10), pp. 1933-1942.

[6] R. A. Vandermeer, P. Gordon: Trans. Aime 1959, vol. 215, pp. 577-588.

[7] T. Sabin, G. Winther, D. Juul Jensen: Acta Materialia 2003, vol. 51 (14), pp. 3999-4011.

[8] A. Ridha, W. Hutchinson: Acta Metallurgica 1982, vol. 30 (10), pp. 1929-1939.

[9] F. Lin, Y. Zhang, N. Tao, W. Pantleon, D. Juul Jensen: Acta Materialia 2014, vol. 72, pp. $252-261$.

[10] F. Humphreys: Acta Metallurgica 1977, vol. 25 (11), pp. 1323-1344.

[11] Y. Zhang, D. Juul Jensen, Y. Zhang, F. Lin, Z. Zhang, Q. Liu: Scripta Materialia 2012, vol. 67 (4), pp. 320-323.

[12] A. English, W. Backofen: Trans. TMS-AIME 1964, vol. 220, pp. 396-407.

[13] D. Juul Jensen: Acta Metallurgica et Materialia 1995, vol. 43 (11), pp. 4117-4129.

[14] K. Mukunthan, E. Hawbolt: Metallurgical and Materials Transactions A 1996, vol. 27 (11), pp. 34103423.

[15] R. A. Vandermeer, R. Masumura, B. Rath: Acta Metallurgica et Materialia 1991, vol. 39 (3), pp. 383-389.

[16] E. Lauridsen, S. Schmidt, S. F. Nielsen, L. Margulies, H. Poulsen, D. Juul Jensen: Scripta Materialia 2006, vol. 55 (1), pp. 51-56.

[17] G. Wu, D. Juul Jensen: Philosophical Magazine 2012, vol. 92 (25-27), pp. 3381-3391.

[18] F. Lin, Y. Zhang, W. Pantleon, D. Juul Jensen: Philosophical Magazine 2015, vol. 95 (22), pp. 24272449.

[19] C. M. Hefferan, J. Lind, S. F. Li, U. Lienert, A. D. Rollett, R. M. Suter: Acta Materialia 2012, vol. 60 (10), pp. 4311-4318. 
[20] C. Xu, Y. Zhang, A. Godfrey, G. Wu, W. Liu, J. Z. Tischler, Q. Liu, D. Juul Jensen: Scientific reports 2017, vol. 7, pp. 42508.

[21] D. Field, L. Bradford, M. Nowell, T. Lillo: Acta Materialia 2007, vol. 55 (12), pp. 4233-4241.

[22] A. Vorhauer, S. Scheriau, R. Pippan: Metallurgical and Materials Transactions A 2008, vol. 39 (4), pp. 908-918.

[23] F. Brisset, A.-L. Helbert, T. Baudin: Microscopy and Microanalysis 2013, vol. 19 (04), pp. 969-977.

[24] Y. Jin, B. Lin, M. Bernacki, G. S. Rohrer, A. Rollett, N. Bozzolo: Materials Science and Engineering: A 2014, vol. 597, pp. 295-303.

[25] W. Truszkowski, J. Kr'ol, B. Major: Metallurgical Transactions A 1980, vol. 11 (5), pp. 749-758.

[26] F. Lin, T. Leffers, W. Pantleon, D. Juul Jensen: Effects of widening during rolling on the subsequent recrystallization kinetics of copper: in: Materials Science Forum: Vol. 753: Trans Tech Publ, 2013: pp. 285-288.

[27] G. Wu, D. Juul Jensen: Materials Characterization 2008, vol. 59 (6), pp. 794-800.

[28] E. E. Underwood: Stereology and Quantitative Metallography: ASTM International, 1972.

[29] S. O. Poulsen, E. M. Lauridsen, A. Lyckegaard, J. Oddershede, C. Gundlach, C. Curfs, D. Juul Jensen: Scripta Materialia 2011, vol. 64 (11), pp. 1003-1006.

[30] Y. Zhang, A. Elbrønd, F. Lin: Materials Characterization 2014, vol. 96, pp. 158-165.

[31] A. Godfrey, W. Cao, Q. Liu, N. Hansen: Metallurgical and Materials Transactions A 2005, vol. 36 (9), pp. 2371-2378.

[32] E. A. Jägle, E. J. Mittemeijer: Metallurgical and Materials Transactions A 2012, vol. 43 (4), pp. 11171131.

[33] Y. Lü, D. A. Molodov, G. Gottstein: Acta Materialia 2011, vol. 59 (8), pp. 3229-3243.

[34] H. Chao, H. Sun, W. Chen, E. Wang: Materials Characterization 2011, vol. 62 (3), pp. 312-320.

[35] G. Speich, R. Fisher: Am. Soc. Metals, Metals Park, Ohio 1966, , pp. 563.

[36] R. A. Vandermeer, D. Juul Jensen: Acta Materialia 2003, vol. 51 (10), pp. 3005-3018.

[37] E. Villa, P. R. Rios: Acta Materialia 2009, vol. 57 (13), pp. 3714-3724.

[38] S. Storm, D. Juul Jensen: Scripta Materialia 2009, vol. 60 (7), pp. 477-480.

[39] R. Vandermeer: Acta Materialia 2005, vol. 53 (5), pp. 1449-1457. 
[40] P. R. Rios, L. Pereira, F. Oliveira, W. Assis, J. Castro: Acta Materialia 2007, vol. 55 (13), pp. 4339-4348.

[41] P. R. Rios, R. Godiksen, S. Schmidt, D. Juul Jensen, R. Vandermeer: Scripta Materialia 2006, vol. 54 (8), pp. 1509-1513.

[42] B. Patterson, S. Grandhi: Stereological analysis of the effect of degree of cold work on nucleation and growth rates during recrystallisation: in: Proceedings of the 36th Riso International Symposium on Materials Science: Roskilde, Denmark, 2015: p. 429-437.

[43] A. Gokhale: Metallurgical Transactions A 1989, vol. 20 (3), pp. 349-355.

[44] Y. Zhang, A. Godfrey, Q. Liu, W. Liu, D. Juul Jensen: Acta Materialia 2009, vol. 57 (9), pp. $2631-2639$.

[45] M. Cook, T. Richards: J INST MET 1947, vol. 73, pp. 1-31.

[46] D. Juul Jensen, T. Leffers: Texture, Stress, and Microstructure 1989, vol. 10 (4), pp. 361-373.

[47] F. Haessner, S. Hofmann: In: Recrystallization of metallic materials.(A79-22801 08-26) Stuttgart, Dr. Riederer Verlag GmbH, 1978, p. 63-95. 1978, , pp. 63-95.

[48] A. Rollett, D. J. Srolovitz, R. Doherty, M. Anderson: Acta Metallurgica 1989, vol. 37 (2), pp. $627-639$.

[49] M. Oyarzábal, A. Martínez-de Guerenu, I. Gutiérrez: Materials Science and Engineering: A 2008, vol. 485 (1), pp. 200-209.

[50] B. Scholtes, R. Boulais-Sinou, A. Settefrati, D. P. Muñoz, I. Poitrault, A. Montouchet, N. Bozzolo, M. Bernacki: Computational Materials Science 2016, vol. 122, pp. 57-71.

[51] L. Madej, M. Sitko, K. Radwanski, R. Kuziak: Materials Chemistry and Physics 2016, vol. 179, pp. $282-294$.

[52] R. Doherty, I. Samajdar, C. Necker, H. Vatne, E. Nes: Nucleation of recrystallisation in cold and hot deformed polycrystals: in: Proceedings of the 36th Riso International Symposium on Materials Science: Roskilde, Denmark, 1995: p. 1-23.

[53] D. L. Olmsted, E. A. Holm, S. M. Foiles: Acta Materialia 2009, vol. 57 (13), pp. 3704-3713.

[54] P. A. Beck, P. R. Sperry, H. Hu: Journal of Applied Physics 1950, vol. 21 (5), pp. 420-425.

[55] G. Fan, Y. Zhang, J. H. Driver, D. Juul Jensen: Scripta Materialia 2014, vol. 72, pp. 9-12.

[56] Y. Zhang, J. Budai, J. Z. Tischler, W. Liu, R. Xu, E. Homer, A. Godfrey, D. Juul Jensen: Scientific reports 2017, vol. 7 (1), pp. 4423.

[57] A. Gokhale, C. Iswaran, R. DeHoff: Metallurgical Transactions A 1979, vol. 10 (9), pp. 1239-1245. 
[58] J. Christian: The Theory of Transformation in Metals and Alloys, Part 1: Pergamon, Oxford, 1981.

[59] Y. Zhang, A. Godfrey, D. Juul Jensen: Scripta Materialia 2011, vol. 64 (4), pp. 331-334.

\section{Figure caption}

Fig.1: Sketches showing the thermal treatments on the 90\% cold-rolled plate. (a) Annealing for hardness tests; (b) Annealing for post-mortem EBSD characterizations; (c) Annealing for in-situ 3DXRD measurements; (d) Annealing for ex-situ EBSD characterizations.

Fig.2: (a) Vickers microhardness as a function of time for annealing at three temperatures. The error bars show the standard error of the mean for measurements on the same sample. (b) Temperature dependence of $t_{R}$, where $t_{R}$ is the time for $50 \%$ hardness reduction.

Fig.3: Evolution of the recrystallized volume fraction $\left(V_{V}\right)$, the interfacial area between recrystallized grains and the deformed matrix per unit volume $\left(S_{V}\right)$, and the contiguity ratio $C_{\operatorname{RexRex}}$. (a) Avrami plot showing $-\ln \left(1-V_{V}\right)$ as a function of annealing time in a double logarithmic plot. (b) $S_{V}$ as a function of $V_{V}$. (c) VMR path plot: $S_{V} /\left(1-V_{V}\right)$ vs. $-\ln \left(1-V_{V}\right)$ in a double logarithmic plot. A solid line is fitted in (c), from which the values of $q$ and $C$ in Eq. 8 are determined. In turn, these $q$ and $C$ values are used to calculate the curve shown in (b). (d) Contiguity ratio $C_{\text {RexRex }}$ vs. $V_{V}$. The solid line in (d) shows the analytical prediction for random nucleation, and the dashed line represents $C_{\operatorname{Rex} \operatorname{Rex}}=V_{V}$.

Fig.4: Nucleation and growth results. (a) Number of recrystallized grains per unit volume $N_{V}$ as a function of annealing time. Annealing twin boundaries (TB) are either ignored or included as normal grain boundaries (GB) when determining the intercept length of the recrystallized grains $D$, which are used in Eq. 4 to determine $N_{V}$. When twin boundaries are ignored, a grain and all of its twins are counted as one grain, otherwise twins are counted as separated grains. (b) Cahn-Hagel boundary migration velocity $\left(G_{C-H}\right)$ as a function of annealing time. The fitted solid line in (b) has a slope of $-0.92 \pm 0.02$.

Fig.5: Increase of the equivalent sphere diameter (ESD) of individual grains as a function of annealing time, measured by 3DXRD during in-situ annealing at $403 \mathrm{~K}$. The arrow marks the growth curve of a grain that continues to grow again after a stagnation period.

Fig.6: Growth of individual grains during ex-situ annealing at 423 K. (a)-(c) Orientation maps in the deformed state (a) and after $10 \mathrm{~min} \mathrm{(b)} \mathrm{and} 35 \mathrm{~min}$ (c) annealing. Boundaries with misorientations larger than $5^{\circ}$ are shown in black. Twin boundaries are shown in white. (d) Boundaries with misorientation larger than $5^{\circ}$ within the deformed microstructure before annealing. Localized shear bands are marked 
576 by arrows. (e) Contours of two recrystallized grains (A1 and A4) after $10 \mathrm{~min}$ and $35 \mathrm{~min}$ are shown on 577 top of the boundary map of the deformed microstructure.

578 Fig.7: Sketch showing the recrystallizing boundary positions for grains A1 and A4.

579 Fig.8: Stored energy density map. The local store energy density is represented in gray scale. The 580 recrystallizing boundaries of grains A1 and A4 after the first and the second annealing steps, and the 581 stationary boundaries are also shown. Two low $E_{S}$ regions ahead of the stationary boundaries or invaded ${ }_{582}$ by the recrystallized grains are indicated by arrows.

${ }_{583}$ Fig.9: Distributions of misorientations between the recrystallized grains A1 (a) and A4 (b) and the in${ }_{584}$ vaded deformed regions during the two annealing steps, and distributions of misorientations across ${ }_{585}$ stationary recrystallizing boundaries for grains A1 (c) and A4 (d).

${ }_{586}$ Fig.10: Sketch showing (a) low-dimensional, non-3D growth, (b) 3D growth with many stationary ${ }_{587}$ boundary segments, and (c) 3D growth with boundary segments migrating at different velocities. 
Table I: Chemical composition (weight percentage) of the material.

\begin{tabular}{cccc}
\hline $\mathrm{Cu}$ & $\mathrm{Ni}(\%)$ & $\mathrm{Mg}(\%)$ & $\mathrm{Al}(\%)$ \\
\hline Balance & 0.002 & 0.002 & 0.002 \\
\hline
\end{tabular}

Table II: Grain areas and average stored energy density. $E_{s, m i g}$ is the average stored energy density within the area that the migrating boundaries sweep during each annealing step. $E_{s, s t a}$ is the average stored energy density in the area ahead of the stationary boundaries.

\begin{tabular}{ccccccc}
\hline & Area & Grain A1 & Grain A4 \\
& $\begin{array}{c}E_{s, m i g} \\
\left(\mu \mathrm{m}^{2}\right)\end{array}$ & $\begin{array}{c}E_{s, s t a} \\
\left(\mathrm{MJ} / \mathrm{m}^{3}\right)\end{array}$ & $\begin{array}{c}\text { Area } \\
\left(\mathrm{MJ} / \mathrm{m}^{3}\right)\end{array}$ & $\begin{array}{c}E_{s, m i g} \\
\left(\mu \mathrm{m}^{2}\right)\end{array}$ & $\begin{array}{c}E_{s, s t a} \\
\left(\mathrm{MJ} / \mathrm{m}^{3}\right)\end{array}$ & $\left(\mathrm{MJ} / \mathrm{m}^{3}\right)$ \\
\hline Step 1 (0-10 $\mathrm{min})$ & 81.5 & 3.3 & & 7.0 & 2.7 & \\
Step 2 (10-35 min) & 392.2 & 3.1 & 2.7 & 25.3 & 2.9 & 3.1 \\
\hline
\end{tabular}



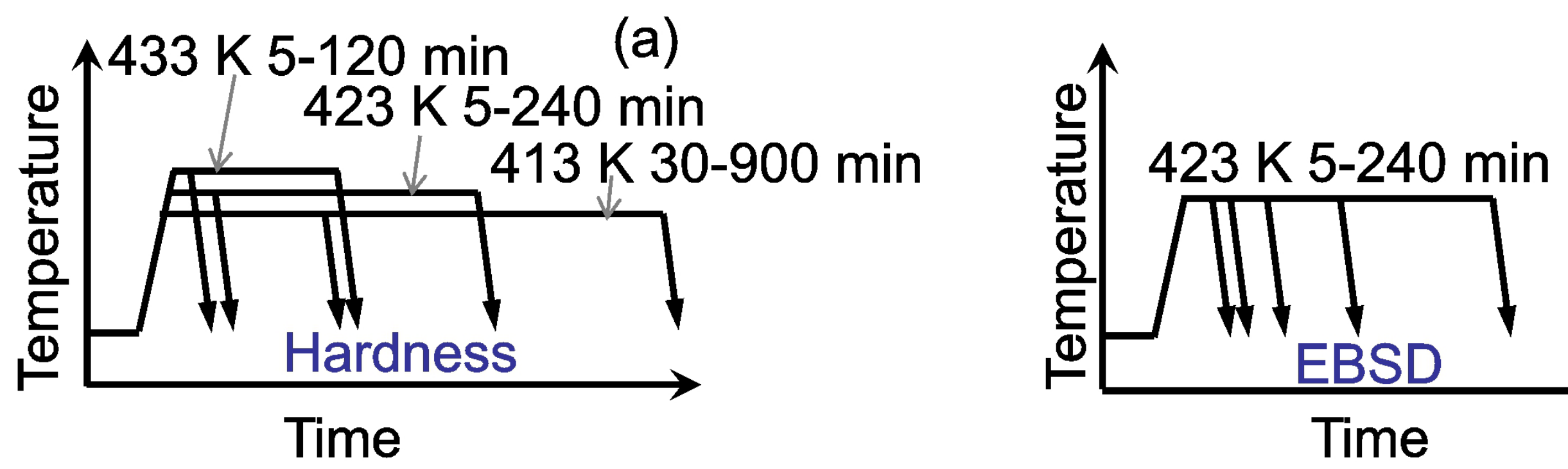

(b)
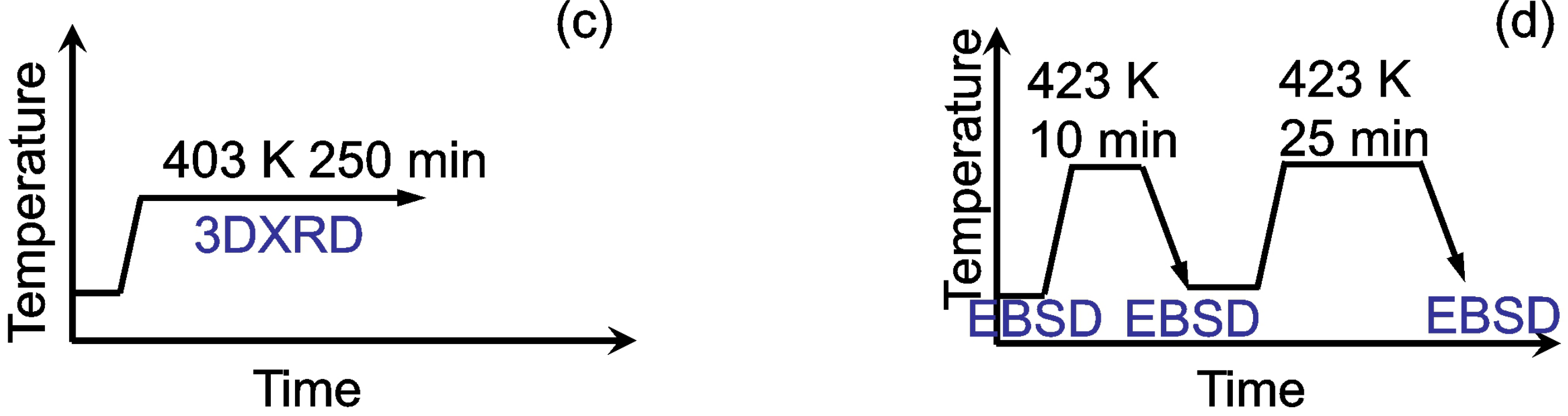


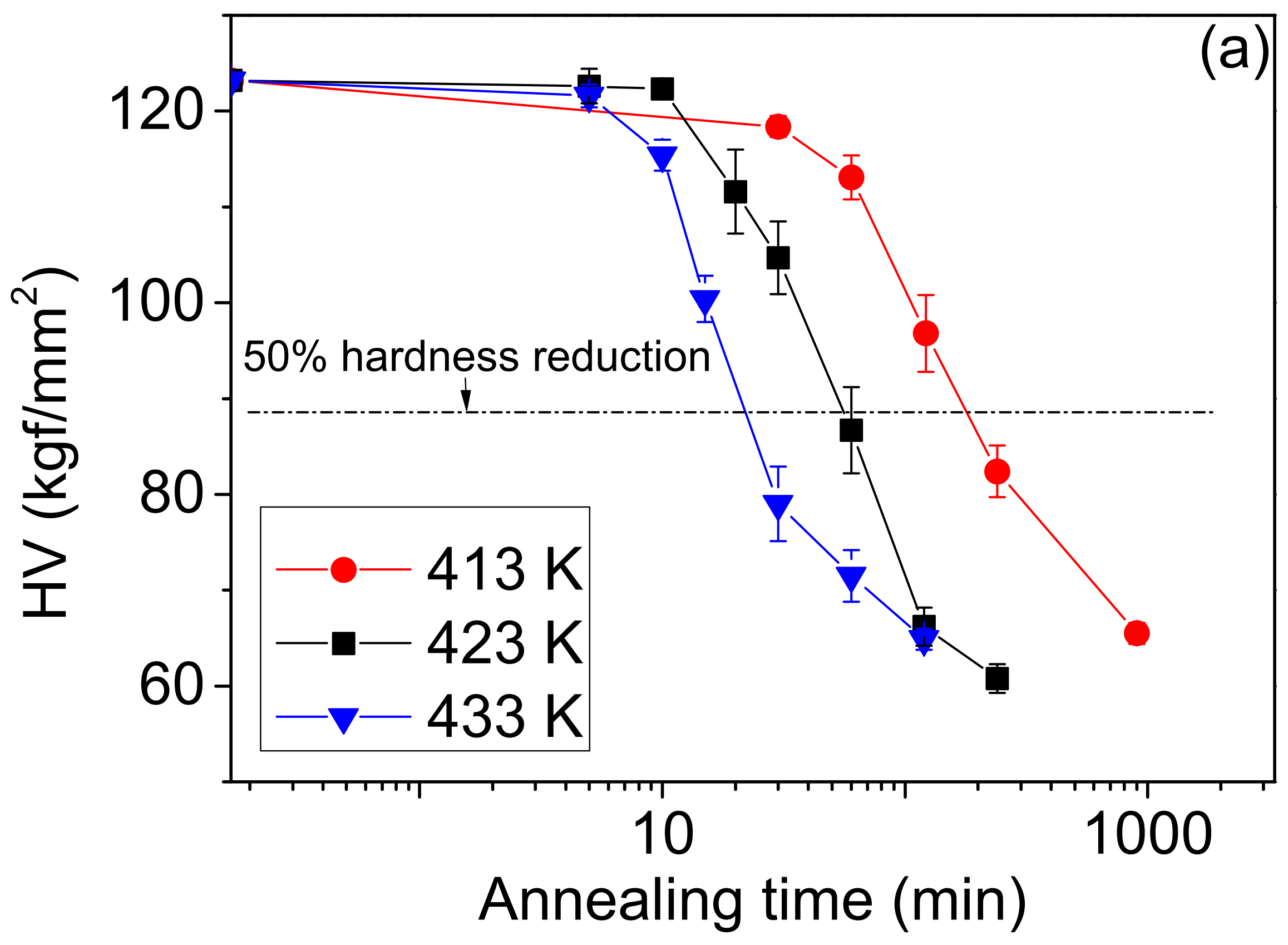




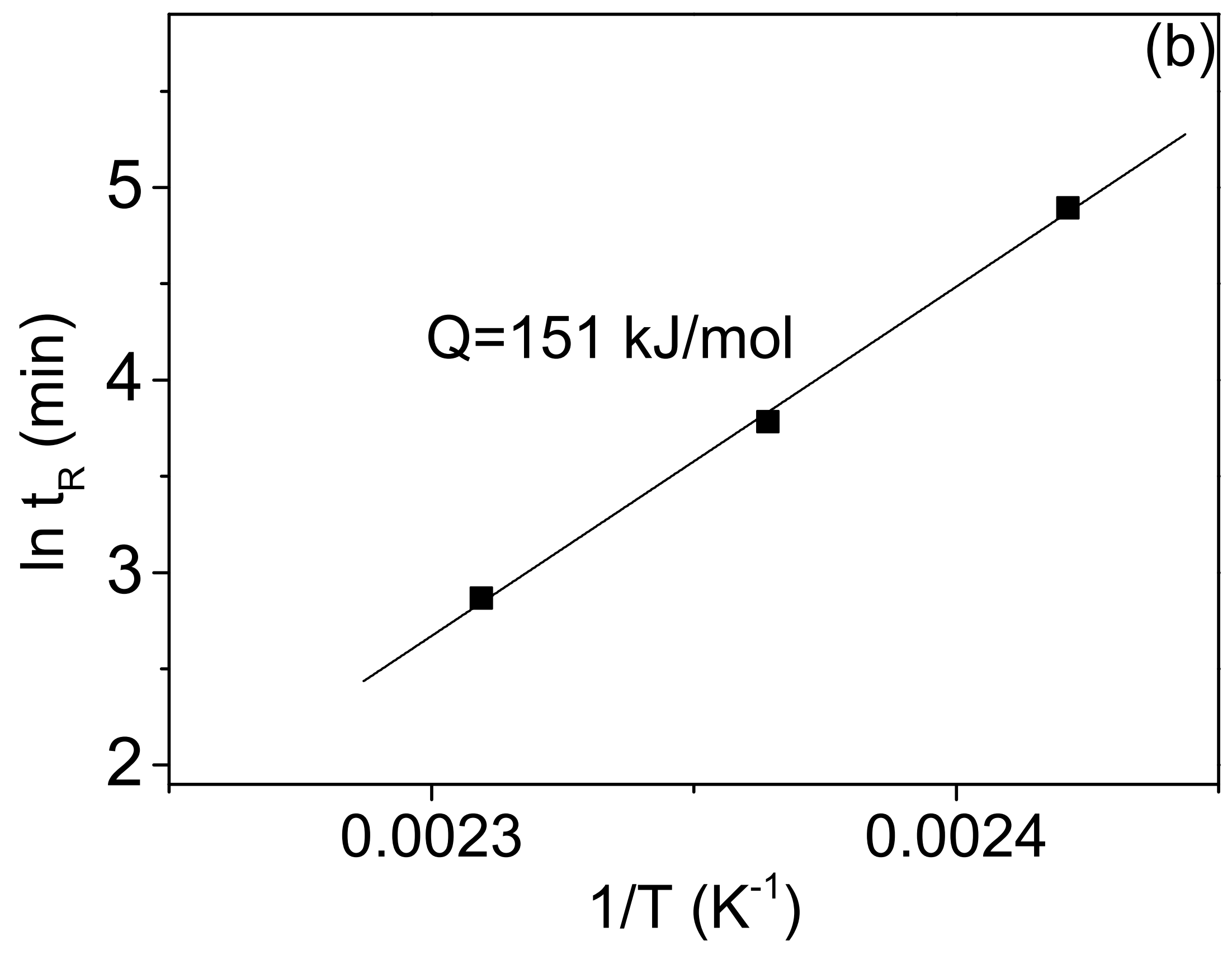



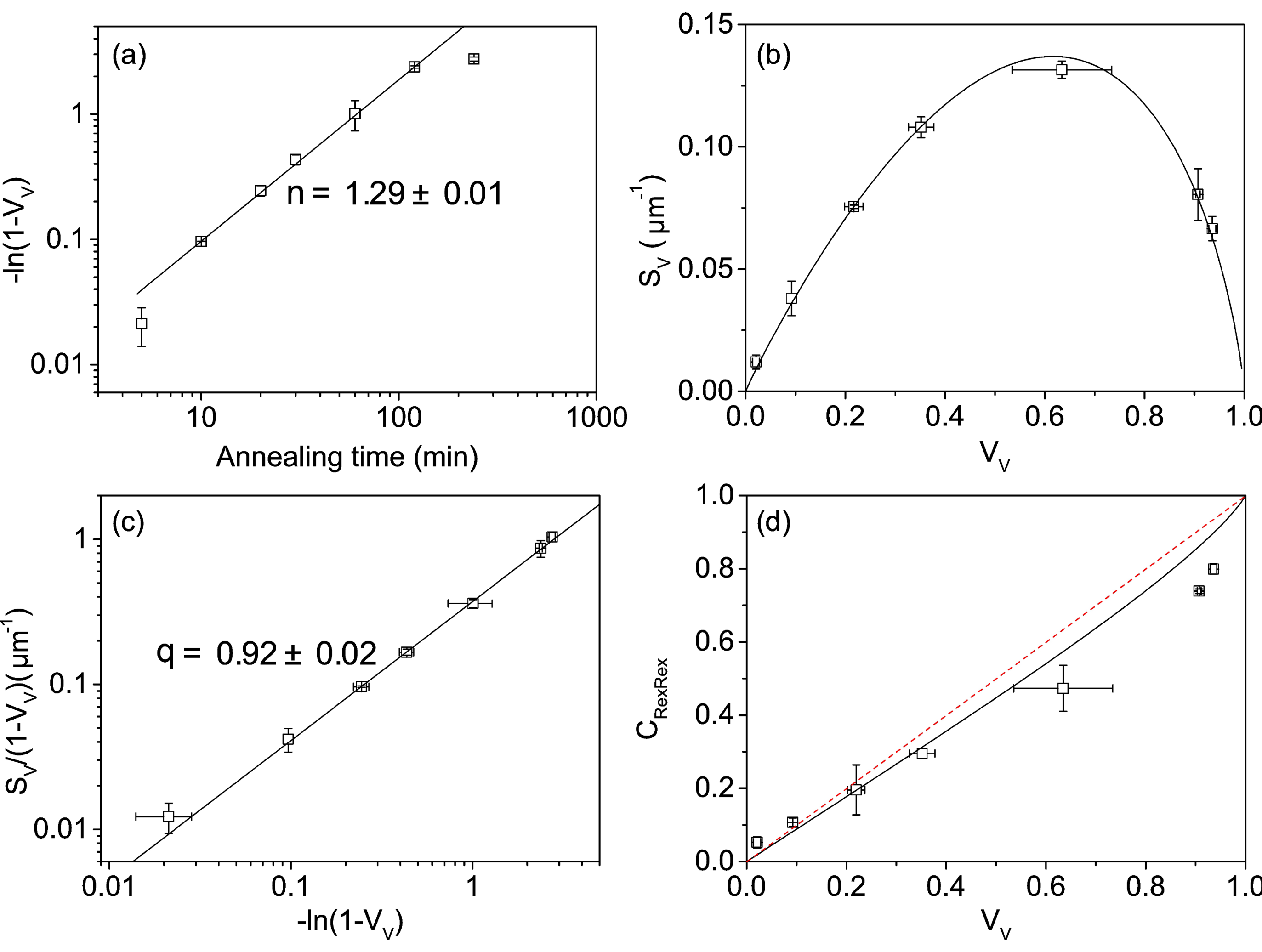


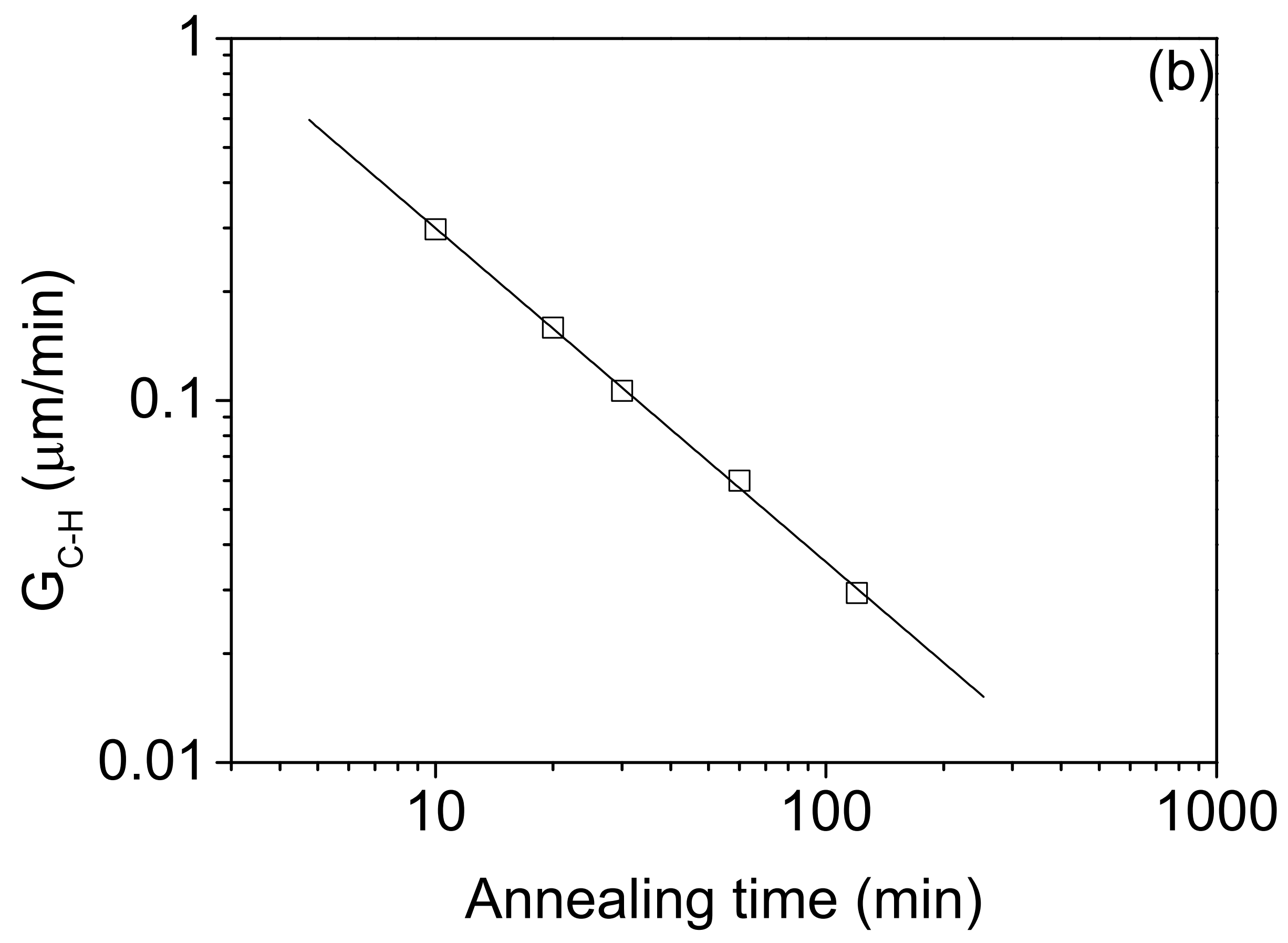




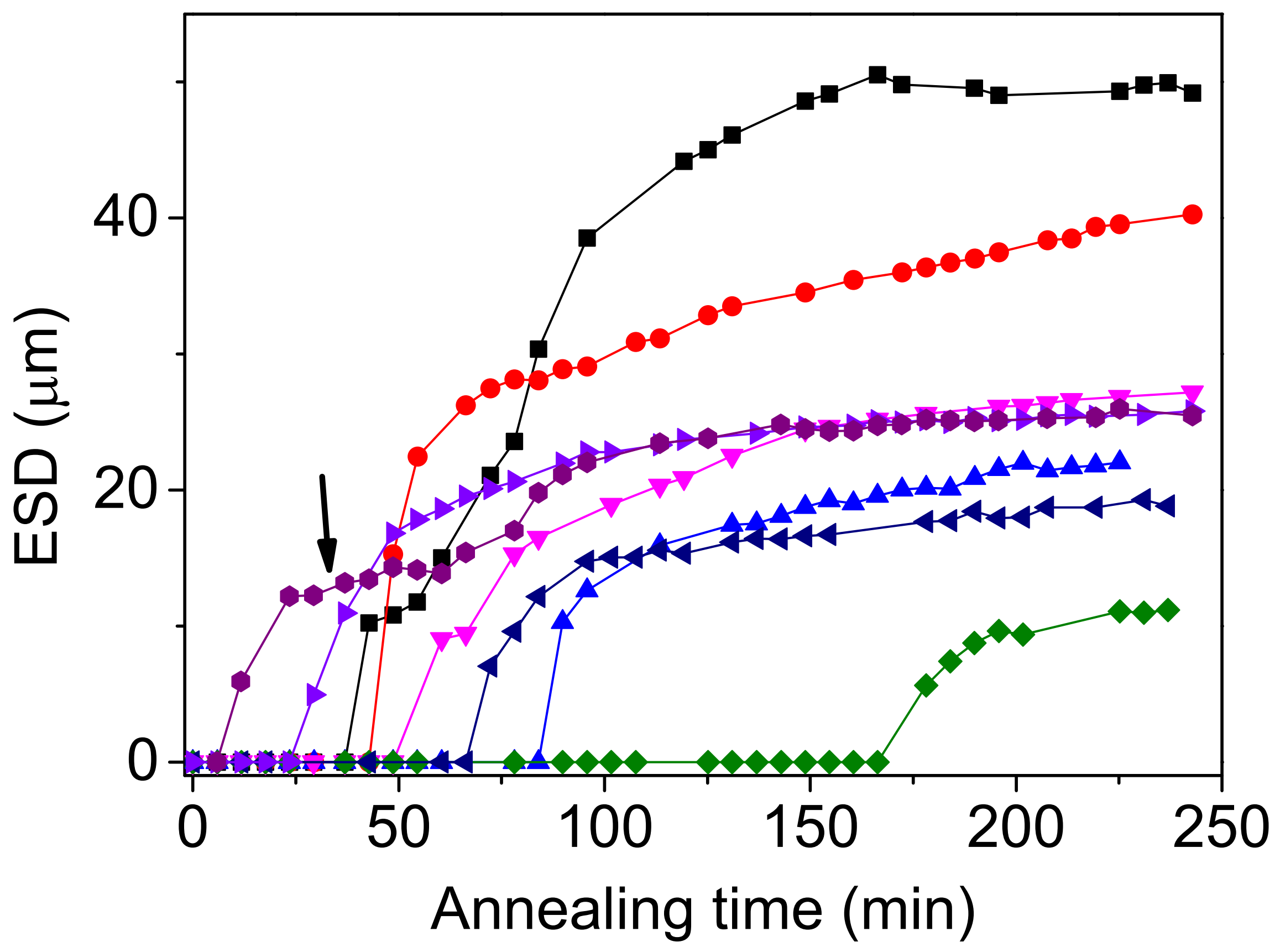


$10 \mu \mathrm{m}$

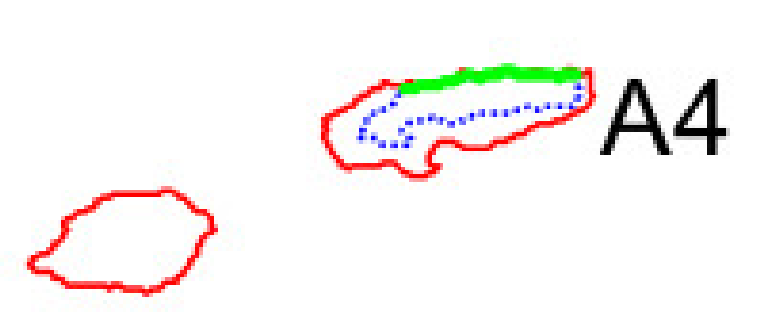

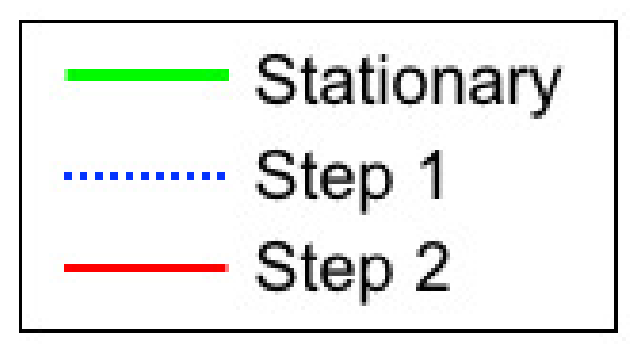
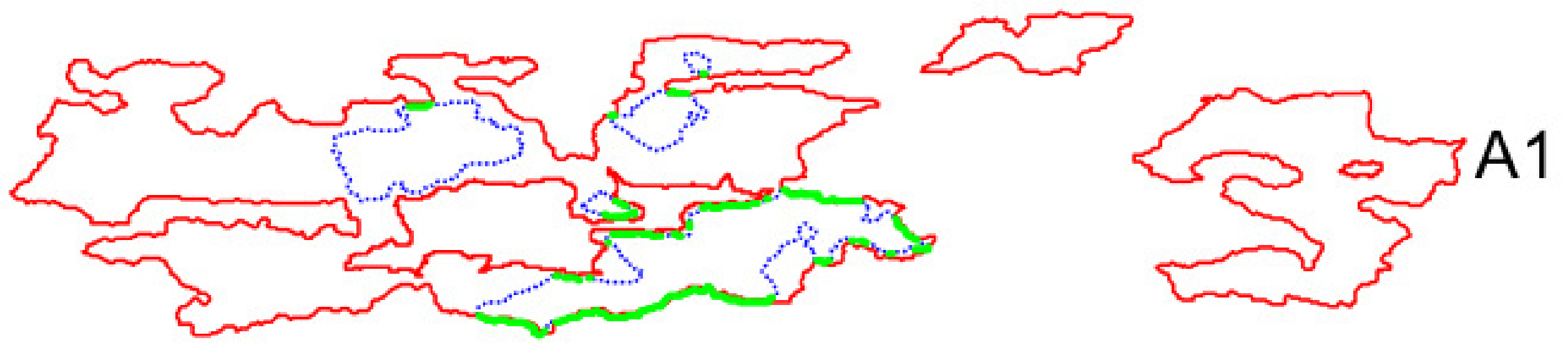

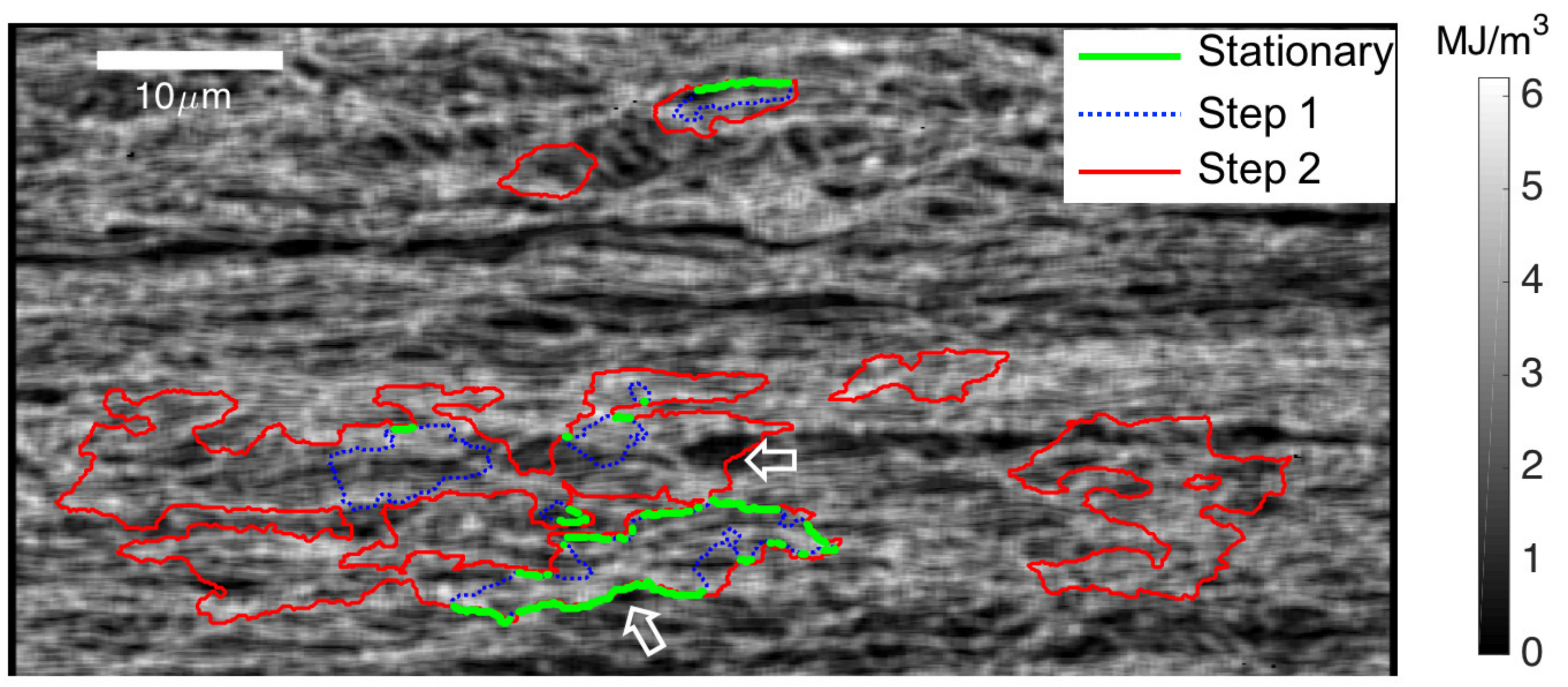

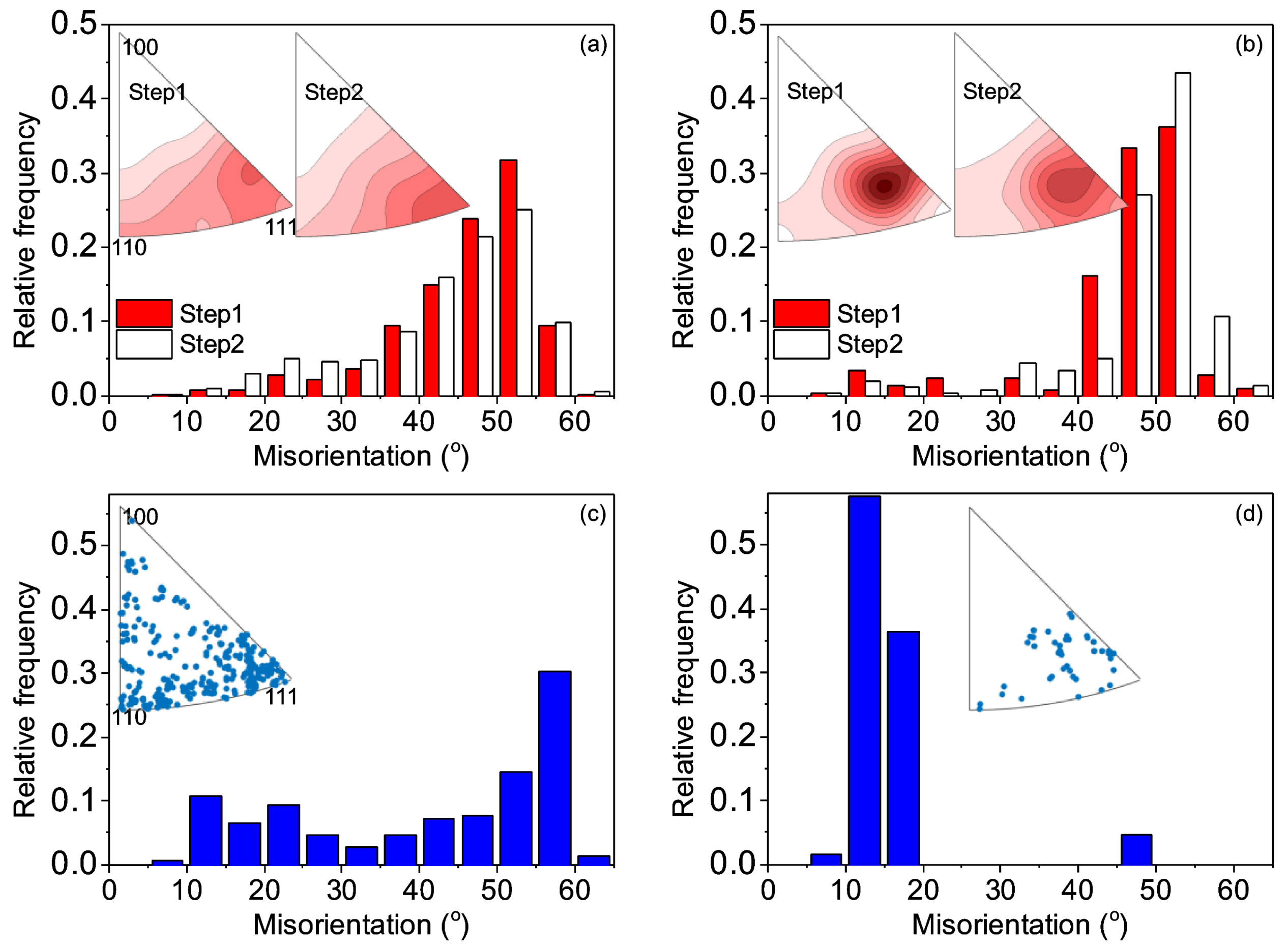
(a)

(b)
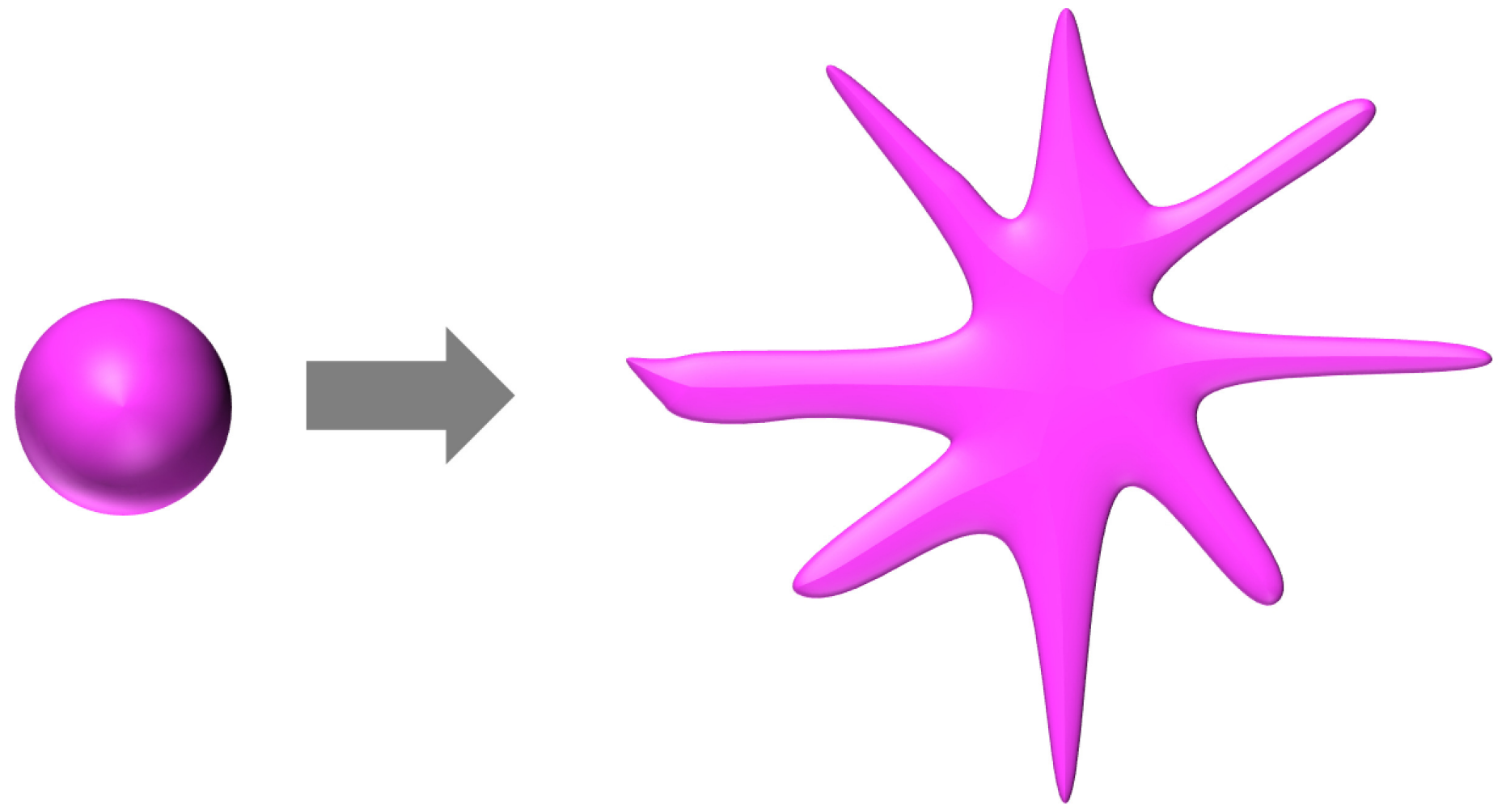

(c)

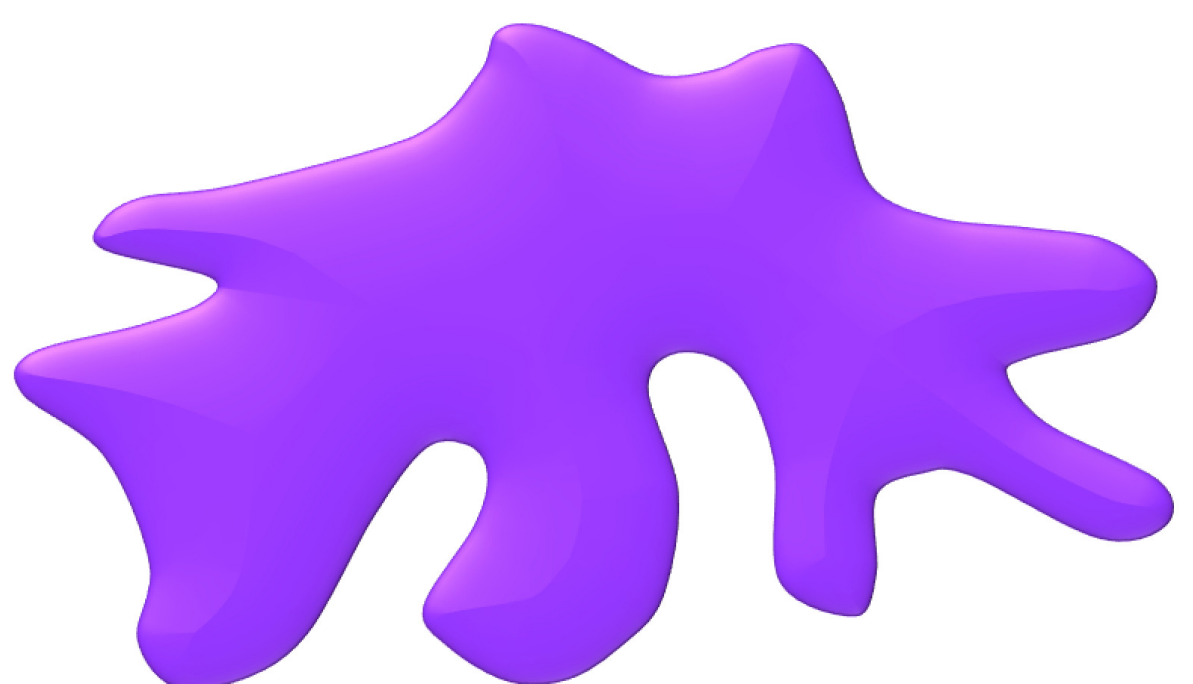

